\title{
Exploring the choices of contraception and abortion among married couples in Tret, rural Punjab, Pakistan
}

Muhammad Shafique Arif

Iram Kamran

Population Council

Follow this and additional works at: https://knowledgecommons.popcouncil.org/departments_sbsr-rh

Part of the Demography, Population, and Ecology Commons, Family, Life Course, and Society Commons, International Public Health Commons, Medicine and Health Commons, and the Women's Health Commons How does access to this work benefit you? Let us know!

\section{Recommended Citation}

Arif, Muhammad Shafique and Iram Kamran. 2007. "Exploring the choices of contraception and abortion among married couples in Tret, rural Punjab, Pakistan." Islamabad: Population Council. 


\section{Exploring the choices of Contraception and Abortion among married couples in Tret, rural Punjab, Pakistan}

Shafique Arif Iram Kamran

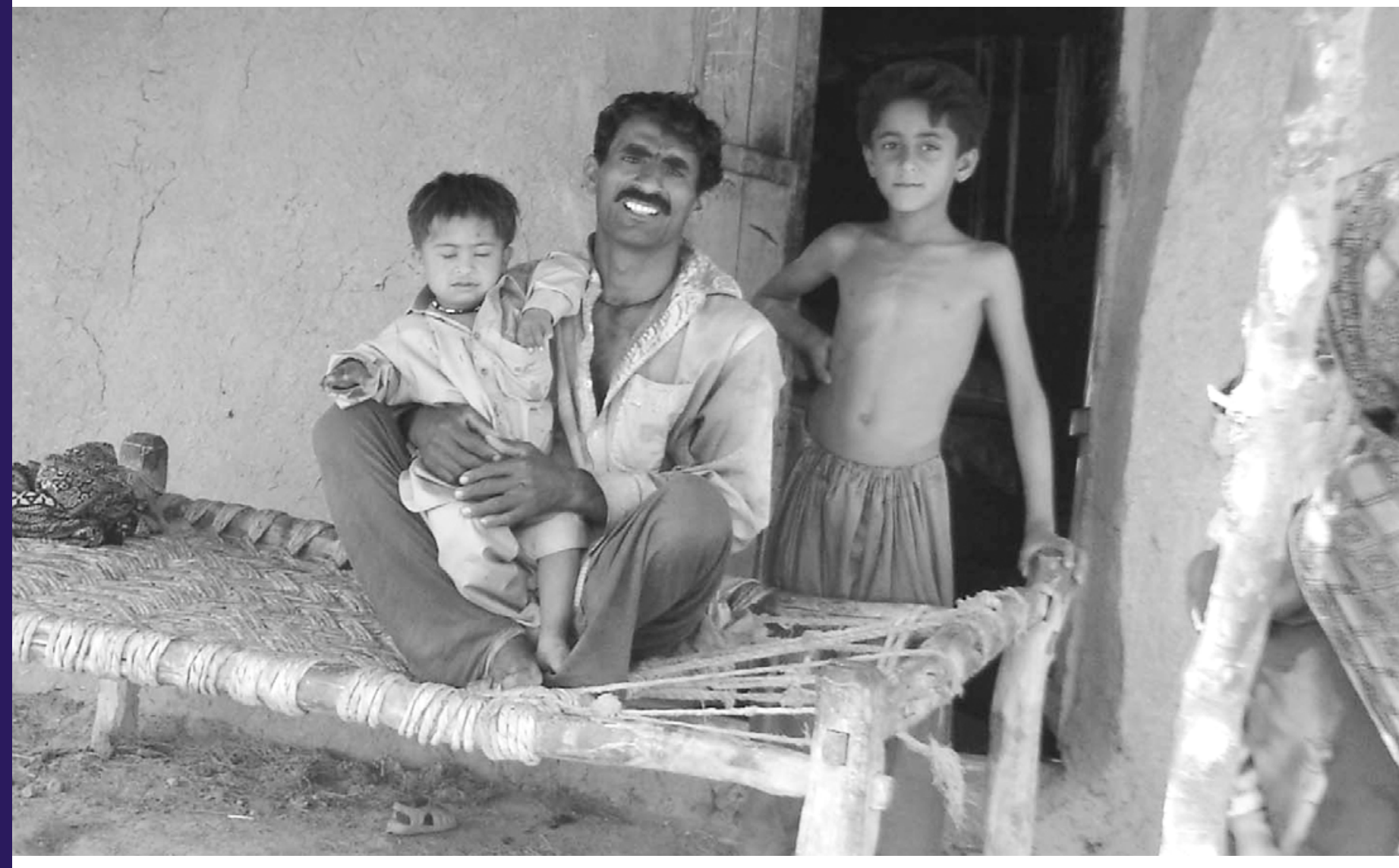





\title{
Exploring the choices of Contraception and Abortion among married couples in Tret, rural Punjab, Pakistan
}

Shafique Arif

Iram Kamran

\author{
Research team \\ Mumraiz Khan \\ Iram Kamran \\ Shaheen Islam \\ Ashfa Hashmi
}




\section{(2) Population Council}

The Population Council, an international, non profit, nongovernmental organization established in 1952, seeks to improve the well being and reproductive health of current and future generations around the world and to help achieve a humane, equitable, and sustainable balance between people and resources.

The Council analyses population issues and trends; conducts research in the reproductive sciences; develops new contraceptives; works with public and private agencies to improve the quality and outreach of family planning and reproductive health services; helps governments design and implement effective population policies; communicates the results of research in the population field to diverse audiences; and helps strengthen professional resources in developing countries through collaborative research and programmes, technical exchanges, awards, and fellowships.

\section{For inquiries, please contact:}

\section{Population Council}

House \#7, Street 62, F-6/3, Islamabad, Pakistan

Tel: 92512277439

Fax: 92512821401

Email: info@pcpak.org

Web: http://www.popcouncil.org

Layout \& Design: Ali Ammad

Printed by: Crystal Printers

Published: February 2007

The Population Council reserves all rights of ownership of this document. No part of this publication may be reproduced, stored or transmitted in any form by any means electronic, photocopying, recording or otherwise without the permission of the Population Council. 


\section{Table of Contents}

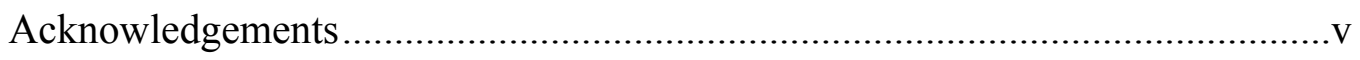

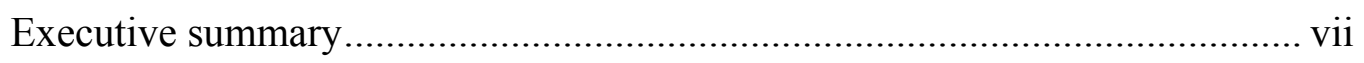

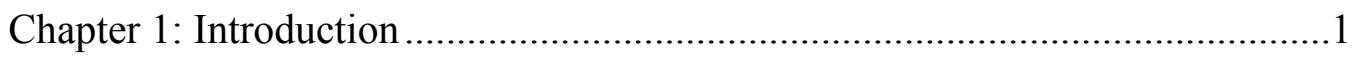

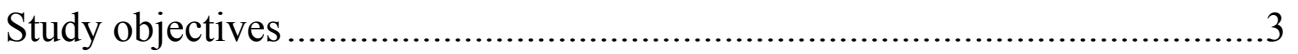

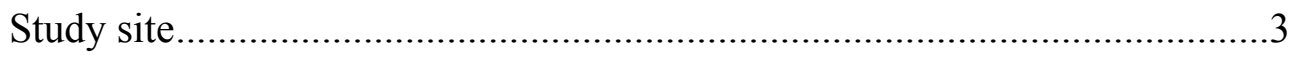

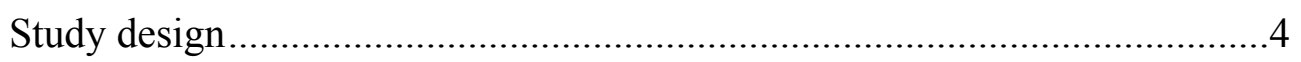

Recruitment process for study participants ..............................................

Topic guidelines for IDIs and FGDs.....................................................6

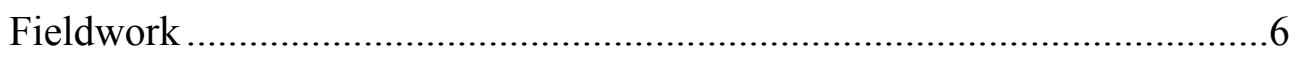

Background characteristics ................................................................

Chapter 2: Reproductive Intentions ......................................................... 9

Perceptions about wanted and unwanted pregnancies ................................9

Wantedness of pregnancy by order..........................................................13

Chapter 3: Factors underlying unwantedness of pregnancies..........................17

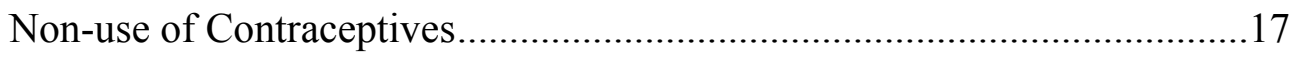

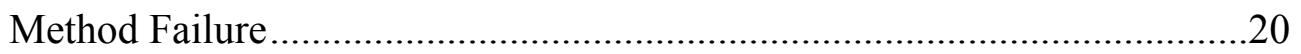

Chapter 4: Contraception and abortion: experiences, communication and costs 23

Spousal Communication ......................................................................23

Public face and individual reality regarding contraceptive use and abortion 27

Comparative Costs of Contraception and Abortion....................................29

Induced abortion as an "alternative" or "backup" to contraception ..............34

Chapter 5: Couple concurrence and discord regarding pregnancy wantedness...35

Chapter 6: Conclusions .........................................................................4

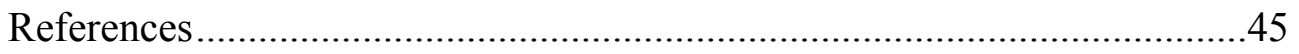

APPENDIX A: Summaries of male and female in-depth interviews ................47

1) Female In-depth Interview Summary \# 01 ..........................................47

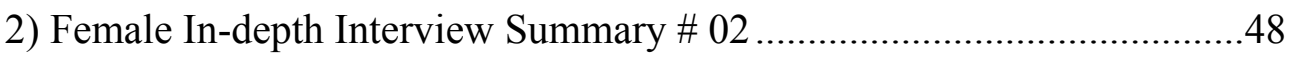

3) Female In-depth Interview Summary \# 03 ..........................................50

4) Female In-depth Interview Summary \# 04 ..........................................51

5) Female In-depth Interview Summary \# 05 ...........................................54

6) Female In-depth Interview Summary \# 06 ............................................56

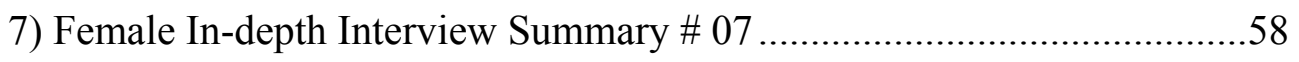


8) Female In-depth Interview Summary \# 08 ...........................................59

9) Female In-depth Interview Summary \# 09 ..........................................62

10) Female In-depth Interview Summary \# 10 ........................................63

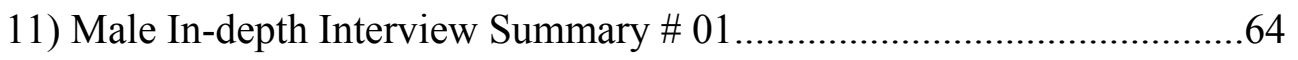

12) Male In-depth Interview Summary \# 02 ............................................65

13) Male In-depth Interview Summary \# 03 ...........................................67

14) Male In-depth Interview Summary \# 04 ............................................68

15) Male In-depth Interview Summary \# 05 ............................................69

16) Male In-depth Interview Summary \# 06 ..............................................70

17) Male In-depth Interview Summary \# 07 .............................................72

Appendix B: Guidelines for in-depth interviews ........................................73

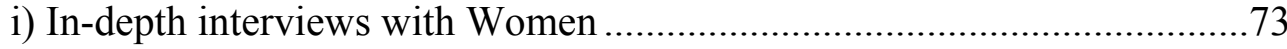

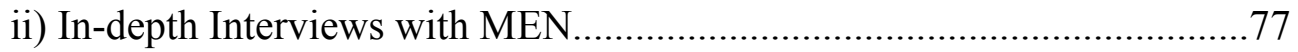

APPENDIX C: Guidelines for Focus Group Discussions ................................8 80

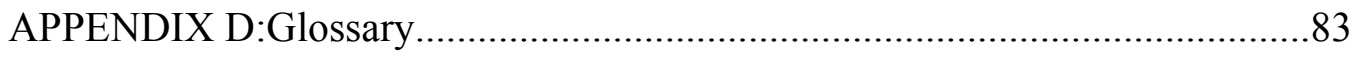




\section{Acknowledgements}

Firstly, we would like to thank "Bill and Melinda Gates Institute for Population and Reproductive Health" for the financial support to conduct this study.

We would like to especially thank Professor Amy Tsui for her input and guidance throughout the study and especially for her invaluable comments to the research team during her visit to Pakistan.

We are indebted to Dr. John Casterline, who greatly assisted in critically reviewing the report. His careful review and comments on the report, significantly improved its clarity for the reader.

We would like to express our deepest appreciation to Dr. Zeba A Sathar, Country Director Population Council, Islamabad, under whose guidance and close supervision, this study was carried out. Without her leadership and persistent help, this study would not have been possible. We owe special thanks to her for her thought provoking comments and feedback throughout the project activities.

Furthermore, we acknowledge the hard work and tireless efforts of Mumraiz Khan, Shaheen Islam and Ashfa Hashmi, who were involved in the study, right from the very beginning. They helped in finalizing the guidelines, data collection and analysis. They also carried out the laborious work of transcription of the indepth interviews and focus group discussions.

We are grateful to Ms. Tahira Abdullah, who took on the responsibility of editing the report at extremely short notice. In addition, thanks are due to Ms. Sabiha Askari for editing the transcripts of the in-depth interviews and focus group discussions.

Finally, but most importantly, we are sincerely grateful to all the survey respondents who participated in our inquiry and remained enthusiastically involved during the interviews and in-depth discussions with great patience. 



\section{Executive summary}

Pakistan has a population of over 163 million, with an annual growth rate of around 2 percent. Fertility has been declining since the late 1980's from a TFR of 6.5 to a current level of 4.8 children per woman. The contraceptive prevalence rate is around 28 percent and unmet need for family planning services is 33 percent (Hakim A., M. Sultan and F.Ud-din, 2001). Unwanted pregnancies are on the rise. More recently, the informal accounts that induced abortion was being used by couples to 'deal with' unwanted pregnancy have been confirmed with a national study showing a fairly high induced abortion rate of 29 per 1000 married women of reproductive age and one out of six pregnancies resulted in induced abortion in Pakistan (Population Council, 2004).

The main objectives of this study are (a) to explore how contraception and induced abortion are perceived as options for avoiding unwanted births by Pakistani men and women, and to what extent they deliberately choose one over the other and why; and (b) to understand the language and ways of talking about reproductive behaviour decision-making by Pakistani women and men.

The fieldwork was carried out in village Tret, a rural area in district Rawalpindi, Punjab province of Pakistan during the months of April and July 2006. In-depth interviews were conducted with ten married women and seven married men. Two focus group discussions were also conducted (one each with men and women).

Couples in Tret had never planned their fertility at the start of their reproductive lives. They never planned the number of children they wanted and when they wanted them in advance. Therefore they never considered the actions they might take to achieve their reproductive goals.

Decisions related to desirability of pregnancy are made post facto: factors such as poor economic conditions, poor health conditions, child rearing problems, age of the youngest child and mother's health are cited more as justifications for and reasons for not wanting another pregnancy. Couples recount the circumstances 
at the time of conception of a pregnancy and then subsequently assess against them the desirability or wantedness of each pregnancy.

Women's unwanted pregnancies start from the second pregnancy onwards, while for husbands that consideration begins from the fourth pregnancy. Women attempt to abort pregnancies that are unwanted by all means even if their husbands are not supportive. They sometimes do this secretly through homebased remedies, because of the seclusion, segregation, mobility and financial restrictions in accessing clinical procedures.

Women are determined and therefore an important question is why they fail to translate their reproductive thoughts/wishes into reality? There are two main factors responsible for unintended pregnancies, the first is non-use of contraceptives and the second is failure of contraceptive methods during their use. There are factors in the Pakistani rural context that that impede women from use of contraceptives: mainly the perception (mostly erroneous) that they are protected by breast feeding, the sheer lack of availability of family planning services, fear of side effects and fear of husbands' opposition. Once they have used or are using a method of contraception, method failure is a frequent cause of an unwanted pregnancy. In particular condom rupture during use is cited again and again. Women also end up with unintended pregnancies due to the more casual attitude of their husbands when they are responsible for buying contraceptives.

Spousal communication regarding contraception and abortion is not very frequent in Pakistani culture. Decisions are usually made after experiencing poor economic conditions, poor health conditions and rearing problems. Women are more likely to realize and give importance to these issues and as a solution they want to space or limit childbearing, while men are least concerned about such issues. This is the point when women raise this issue with their husbands and try to make them realize the intensity of their reproductive intention. As a result sometimes men agree to use contraceptives but sometimes they oppose them due to religious concerns, fear of side effects and fear of retribution. Due to this lack 
of concurrence, women end up having more children than they desire, unless this divergence converts into convergence.

Husbands and wives do not generally discuss induced abortion as an option to avoiding an unintended pregnancy prior to its occurrence. Usually when couples have had a few mistimed pregnancies, they do discuss and decide where to go for induced abortions.

Spousal communication does not always end in concurrence. However, the intensity of intentions can be measured by the actions taken by women and men themselves. Our interviews show that some women did make an independent decision to have an induced abortion in the case of unintended (unwanted or mistimed) pregnancy. In a few of these situations it was an unintended pregnancy for the woman but an intended one for the husband.

A clear finding from this study is that people think and behave differently depending on the public/community versus private/individual level. The study found that people oppose induced abortion when they talk publicly but they accept the situation (willingly or unwillingly) when they themselves have to face their own unwanted pregnancy.

While making decisions about the use of contraceptives or induced abortion, women do weigh the costs and benefits of each of the options. There are financial costs, social costs and health costs involved in the choice between contraception and abortion. Both abortion and contraception choices are translated into monetary terms. Contraceptives are less expensive and induced abortion is socially unacceptable. They are more reluctant to talk about induced abortion than about contraceptives. The use of contraceptives as well as induced abortion have health problems but these problems are more strongly associated with induced abortions.

Despite the fact that women favoured contraceptives more than induced abortion, they still opted for induced abortion. The reason for having an induced abortion was the non-availability of more effective contraceptive methods and lack of contraceptive knowledge at the time of their unwanted pregnancy, which resulted in induced abortion. There are now two community health workers 
(LHWs) and a basic health unit (BHU) in the community and they have recently started providing family planning services in Tret. Now women have better family planning choices therefore, they prefer contraception compared to induced abortion for fertility control.

It was seen that women in our study are generally practicing induced abortion as a backup for contraceptive methods (including failure) to regulate their fertility.

Men generally do not report induced abortions at all, or tend to report induced abortions as spontaneous abortions. Possible reasons for this under-reporting are: (a) either men do not know about the occurrence of that pregnancy which results in an induced abortion, or (b) they do not know the exact outcome of the pregnancy, or (c) they do not want to disclose the abortion publicly. On the other hand, women are generally more accurate in reporting the outcomes of their pregnancies. Seeking information in chronological order about each pregnancy helps women in recalling events associated with each one. 


\section{Chapter 1: Introduction}

Pakistan has a population of over 163 million, with an annual growth rate of around 2 percent. Fertility has been declining since the late 1980s from a TFR of 6.5 to a current level of 4.8 children per woman. The contraceptive prevalence rate is around 28 percent and unmet need for family planning services is 33 percent (NIPS, 2001). Unwanted pregnancies are on the rise, with the majority of couples wanting to control fertility, but a significant proportion of couples want to postpone their next pregnancy also. Every fourth birth in the developing world is unwanted, with the number of pregnancies that are unwanted even higher (Casterline \& Sinding, 2000). The main reasons for unwanted pregnancy are non-use, inconsistent use or failure of contraceptive methods (WHO, 2004).

The challenge for policy and programs in reproductive health is the rather low contraceptive prevalence rate, a rate that is not even commensurate with a total fertility rate of 4 , leave alone one that will lead to the replacement levels of fertility envisaged for the year 2020 in Pakistan's Population Policy 2002. Family planning is critical in saving maternal and newborn lives by preventing pregnancies, especially unwanted pregnancies and unsafe induced abortions. Unmet need for family planning implies that the obstacles to the use of contraception for avoiding unwanted pregnancies are largely insurmountable. There are number of factors which hinder women's contraceptive use in Pakistan but some play a crucial role: women's perceptions that their husbands disapprove of contraception; fear of side effects of contraception; and concerns about the religious, social and cultural acceptability of contraception, as reflected in the respondents' approval of specific methods, their concerns about approval by others, and their fear of divine retribution if they contracept (Population Council, 1997). Non-availability of family planning services, high financial costs and concerns about the efficacy of methods are the main factors in the high unmet need for family planning. Unmet need results in unwanted pregnancies, which in turn leads to unwanted births, because in most societies a large proportion of unwanted pregnancies are carried to term (Casterline and Sinding, 2000) 
More recently, the informal accounts that induced abortion was being used by couples to 'deal with' unwanted pregnancy have been confirmed with a national study showing a fairly high induced abortion rate of 29 per 1000 married women of reproductive age and one out of six pregnancies resulted in induced abortion in Pakistan (Population Council, 2004). According to the study, 890,000 induced abortions occurred each year in Pakistan. Since abortion is illegal in Pakistan, the majority of these are unsafe abortions - performed by unskilled service providers, mostly under unhygienic conditions.

The main objectives of this study are to explore the decision-making process surrounding fertility choices. We want to investigate, in depth, the meaning of fertility preferences. The enquiry is aimed to get at the meaning of a birth which is "unwanted" or "mistimed" by exploring the degree to which individuals have planned for fertility preferences; how deeply this is felt (precision, intensity, salience and stability over time); and what the mother's/father's self-assessment is of the costs of becoming pregnant at a time that one or both had wished to avoid a pregnancy. Subsequent to experiencing one or more wanted and/or unwanted pregnancies, we would like to investigate how choices are made about using contraception and induced abortion as options for avoiding an unwanted birth.

This is a pilot study that focuses on decision making and choices. The study results are expected to inform a broader, subsequent study that is planned to take place not only in Pakistan but also concurrently in Nigeria, Peru, Mexico and USA. The Population Council is conducting the Pakistani component of this project. It is being undertaken in collaboration with the Gates Institute at Johns Hopkins University, Bloomberg School of Public Health. The Gates Institute is the research partner for the other four countries as well. 


\section{Study objectives}

- To gain greater insight into how couples understand the meaning of "unwanted" vs. "mistimed" births;

- To explore how contraception and induced abortion are perceived as options for avoiding unwanted births by Pakistani men and women, and to what extent they deliberately choose one over the other and why;

- To understand the language and ways of talking about reproductive behaviour decision-making by Pakistani women and men.

\section{Study site}

The fieldwork was carried out in village Tret, a rural area in district Rawalpindi, Punjab province of Pakistan. Individuals were recruited from the general population of the selected community. Tret is 26 kilometers from Islamabad. It is situated off the main road, which leads to Murree (a hill station). The village is located in a hilly area and has neither paved streets nor a drainage system. Most of the male residents are employed in low level government jobs. Daily waged labour is also a major source of livelihoods. The majority of women do not do any waged work. Drinking water is the major problem in the area, especially in summer, when women have to fetch water from long distances away from home. Poultry farming is a major industry in the area, but the owners of these farms are from outside the area.

There are two schools in the community, a girls' middle and a boys' primary school. Syed and Abbasi are the main castes in the village. The village consists of 2,530 households with a population of 7,000 to 10,000 .

The village is fairly well served in terms of health services: there is a Basic Health Unit (BHU) and two functional Lady Health Workers (LHWs) ${ }^{1}$ in the community. The BHU was established about 10 years ago and LHWs started working recently (since 2002). There is also one private hospital in the

\footnotetext{
${ }^{1}$ LHW is a female community health worker with at least eight years of schooling, employed by the Government in the community where she resides. She has a target population of 200 households. She visits each household at least once in two months; provides health education, treatment of minor ailments and provides non-clinical contraceptive methods (condoms and pills) to married women of reproductive age.
} 
community with male and female medical doctors. Two traditional birth attendants also operate in the community.

\section{Study design}

Qualitative data collection techniques, non-structured in-depth interviews and focus group discussions, were used to collect information from married men and women. In-depth interviews were conducted by using the free-style technique, which was used to encourage respondents to 'tell their story' rather than answer questions in any specific domain. The study includes a total of 17 in-depth interviews (10 with women and 7 with men) and two focus groups, one with men and the other with women. The respondents for in-depth interviews were married women of reproductive age, with at least 4 living children, as it is after those parities that women start to face stringent choices regarding further childbearing. Seven in-depth interviews were conducted with married men (the wives of 5 men were also among the women interviewees) to investigate decision-making and the tension or concurrence between men and women in reproductive decisions.

Data collected through in-depth interviews and focus group discussions provided rich information on women and men's intentions and couple communication in making decisions and actions taken for fertility choices.

\section{Recruitment process for study participants}

\section{i In-depth interviews}

The team of researchers selected a rural community near Rawalpindi city. The site was chosen purposively as it is neither urban nor entirely remote rural. Since the village is located off a main road and is also well served in terms of health services and transport, we assumed that the reproductive choices and behaviour would be reflective of average communities in rural Punjab.

The researchers used anthropological approaches for identification of respondents. The team visited the selected community repeatedly for 8 to 10 days. During the visits to the community, rapport was developed with the 
residents by talking to people on different topics. In this duration, the interviewers conducted informal interviews with several residents and tried to single out respondents who were likely to have experienced an unintended pregnancy. Eventually, all respondents met the following criteria:

- Married men/women of reproductive age with at least four living children;

- Willingness to participate in the study.

If the respondent was eligible to participate, the recruiter discussed the study objectives and a suitable time for the interview with the potential respondent. After getting his/her consent for participation, the recruiter set up a suitable time for the interview. The location chosen for the interview was mutually agreed upon. To avoid the fear of information loss, a tape recorder was used if the respondent permitted. The Internal Review Board (IRB) of the Population Council in New York (USA) approved this study in April 2006.

Senior research staff of the Population Council, Islamabad Office, carried out the interviews themselves to ensure the highest quality of responses. These researchers have considerable experience in conducting qualitative research and sensitivity in handling the topics under discussion.

\section{ii. Focus group discussions (FGDs)}

The main purpose of the focus group discussions (FGDs) was to learn how men and women (a) talk about social norms regarding abortion and contraception, (b) perceive contextual influences on abortion and contraceptive behaviour, and (c) view the relative choices of contraception and abortion for preventing pregnancy and births.

Participants for the FGDs were selected during the team's stay in the community. The selection criteria for FGDs were:

- Married men/women of reproductive age with at least 4 living children;

- Willingness to participate in the interview; 
- Screening of socio-economic status, so the group would be socioeconomically homogenous.

\section{Topic guidelines for IDIs and FGDs}

The suggested topics for the women and men's in-depth interviews included the following:

- A full pregnancy history including context surrounding becoming pregnant, reaction to discovery of pregnancy, expectations of how to manage the pregnancy, outcome of the pregnancy ended and pressures surrounding each of the pregnancies;

- Experiences with the use of family planning;

- Decision-making and communication with spouses and other family members regarding reproductive choices;

- Costs surrounding contraception and abortion.

The average length of each in-depth interview was about one hour and it was conducted in the local dialect (Potohari).

The guidelines for the FGDs included the following perceptions:

- Family planning in the community;

- Perceptions of the process of decision-making about the use of contraception;

- Community attitudes towards abortion, including social stigma and possible repercussions;

- Circumstances under which there might be perceived preferences for abortion;

- Communal consequences of having an induced abortion.

\section{Fieldwork}

Fieldwork began in April 2006 and continued until July 2006. Data were collected in two phases. In the first phase, half of the work was completed and data were analyzed and shared in a meeting held on May 9, 2006 with stakeholders and other researchers. Fortuitously, Dr. Amy Tsui was present at the seminar and 
gave her inputs on the research carried out thus far. This analysis helped in identifying the information gaps, which were then covered in the second phase for the rest of the interviews. Some of the earlier respondents were re-contacted on the basis of prior consent obtained at the time of the first interview.

Interviews were conducted in the free-style technique, where respondents were asked to recount their reproduction-related events in a story telling manner. Rapport building prior to each interview helped to get these truthful insights and to revisit the respondents. Women were found to be quite welcoming when revisited, but some of the men showed reluctance on the second or third visit. For example, one respondent mentioned his experience of induced abortion quite comfortably on the first visit, but the second time he was hesitant and tried to hide some information. Similarly, another male respondent refused to be interviewed the second time. Women generally gave a warm response and some may have considered it a form of catharsis to share their experiences with women from outside of their community.

\section{Background characteristics}

\section{a) Women}

All the respondents for the in-depth interviews were rural women, mean age 35 years, and mean age at marriage 16 years. On average, they had 7.8 pregnancies, 5.7 live births and 5.2 living children (2.8 sons and 2.4 daughters). Three out of ten female respondents had never been to school, two could not complete primary school and three had completed primary while one had completed middle school and one was a matriculate. Women from the village reported nonavailability of a nearby education facility 30-40 years ago as the reason for their low levels of schooling. Women who completed middle school were the ones who had moved here from outside, presumably after marriage. None of the women was employed. All respondents belonged to lower middle class or poor families because they were mostly engaged in daily wage labour activities and their basic problems were to feed their children and to bear the expenses of local schooling. 


\section{b) Men}

In total, seven in-depth interviews were conducted with men, of which five were husbands of women interviewed while the other two were not husbands. All the men had some years of schooling. One respondent had completed high school, another had passed middle school, and the rest had primary level schooling. All male respondents got married to women within their families through arranged marriages and with the exception of one, were living in a nuclear family setup at the time of the interview.

Respondents belonged to either lower middle or poor classes. Although all were engaged in some economic activity, they were mostly in low paid jobs such as drivers, waged workers, or daily labourers. 


\section{Chapter 2: Reproductive Intentions}

\section{Perceptions about wanted and unwanted pregnancies}

It is clear that couples in Tret had never planned their fertility in the beginning. They never planned in advance the number of children they wanted, when they wanted them and what actions they might take to achieve their reproductive goals.

"We never planned and never even discussed (reproductive goals) with each other (husband and wife). When we got married, it was the time of shyness. I used to feel shy and hesitated in talking to my husband.

Therefore, we never discussed such things." (FIDI- 05)

Another woman expressed her views in this way:

"(We) never planned the next child. We did not know about anything (family planning) at that time. I used to think that I have got a daughter and that's enough. But I conceived only three months after the last birth. I did not want it at all. I did not want the second pregnancy so soon." (FIDI-04)

One reason for her shyness or lack of communication was due to fear of her husband's temper.

"I am afraid of my husband. He gets irritated and loses his temper very quickly. Therefore, we never talked about it." (FIDI-04)

Decisions related to desirability of pregnancy are made post facto, after the experience: factors such as poor economic conditions, poor health conditions, child rearing problems, age of the youngest child and mother's health are cited as reasons for not wanting another pregnancy. Couples recall the circumstances at the time of conception and then subsequently assess the desirability or wantedness of each pregnancy. One of the women recounted: 
"It was my desire that the last child should be a bit older before I conceive again. But I conceived before that. Everyone started saying I conceived too early. I pray that it should not happen again in future."(FIDI-08)

Another woman described a mistimed pregnancy as follows:

"I thought the first child was too young and I was pregnant again. What was I to do? Things happen according to God's will." (FIDI-08)

Another woman expressed her feelings thus:

"It was my wish that I should conceive when my youngest child started going to the toilet on his own." (FIDI-08)

It is common that husbands and wives do not talk about their fertility preferences. However, there is general convergence that the first pregnancy is always a wanted pregnancy, even if couples never talk about it. The first pregnancy is desired by the husband, the wife, the family, and by other relatives and as soon as possible. This pregnancy actually establishes that the couple is fertile.

"I was very happy at my first pregnancy. All the family members were so happy and my husband also felt very happy that I have got pregnant soon after marriage." (FIDI-03)

Another woman had to go through a different experience:

"I wanted to be pregnant soon after my marriage. The in-laws also wanted a child soon. It took me some time to get pregnant but my in-laws started saying that they would wait for 5 years and if I did not get pregnant then their son would go for a second marriage. I was so scared and worried during all this time. Thank God that I got pregnant three years after marriage." (FIDI-10)

Level of desirability of pregnancy (wanted, mistimed, unwanted) is based on existing situations. For example, if the woman is not in good health or the youngest child is too young at the time of the next pregnancy, then it will be declared as mistimed. One of the women who had a mistimed pregnancy gives this justification: 
"The pregnancy happened too early, because my child was too young and I was having some health problems and there was no one in the household to help me in rearing the children." (FIDI-06)

If a couple already has a large number of living children and has limited financial resources and problems in rearing children then the pregnancy is clearly to be classified as unwanted.

"I did not want any more children because we were poor. My husband was jobless. No money was available. I did not want any more because it is very difficult to rear children." (FIDI-04)

A wanted pregnancy is usually articulated when men and women want to prove parenthood and want more children, especially more sons. For example, if the respondent wanted to have a pregnancy at the time it occurred and the respondent was happy to be pregnant, that means it was a wanted pregnancy.

Similarly, if respondents wanted to have more children but did not want to be pregnant at the time when it occurred and did not have happy feelings, such a pregnancy is termed as mistimed. The concept of "unwanted" pregnancy indicates that a respondent did not want to have more children at any cost. In this situation if she got pregnant and she was unhappy then it was considered an unwanted pregnancy. The strength of decision-making and determination to terminate a pregnancy is stronger among unwanted pregnancies as compared to mistimed pregnancies.

The major factors that influence desirability of each pregnancy are the following:

\section{Economic}

Respondents wanted to stop having children because of economic reasons. They felt that they did not have enough resources for rearing children. They wanted to provide education and health care to their children. As stated by one of the female respondents: 
"I have three daughters and two sons, which is enough. I cannot take care of any more children. There are many problems related with children because we have to educate them and their food should also be good and if I keep on producing children then there would be problems for them in future. It is easy to keep children in the womb for 9 months but it is hard to deliver them and even harder to rear them." (FIDI-03)

\section{Women's health}

The mother's health is taken into account while making decisions for fertility control. If the health of the mother is not very good or if her health problem is aggravated due to pregnancy, then couples decide not to have more children.

"My daughter (last living child) was born in hospital. My husband came to the hospital where the doctor advised him:" your wife is too weak internally and she cannot bear more children and it would be hard to save her life if she gets pregnant the next time so it is better to use family planning." I made him understand that now I can't bear more children. After the doctor's advice he got worried and said that three sons and one daughter are enough." (FIDI-08)

\section{Age of youngest child}

Ages of the existing children are another factor. When children are deemed "too young" a pregnancy is considered mistimed. Mothers fear that the next pregnancy may affect the care given to the youngest child or they will have to stop breastfeeding. Mothers also fear that back-to-back pregnancies (short birth intervals) may harm their health or the young infant's health or both.

"I did not want this pregnancy very quickly because my son was just 10 months old. That is why I took tablets to terminate the pregnancy." (FIDI01)

Older children are an embarrassment, and play an important role in making the decision not to have more children. Respondents with grown up children mentioned that they felt embarrassed if they were pregnant. Therefore, if they became pregnant in the future then they would try to seek an abortion. 
"My elder son is 13 years old. It does not look good to produce more when children are grown up. Now we have to be careful in front of our children so that they cannot get to know of such things." (MIDI-01)

\section{Wantedness of pregnancy by order}

Information was collected from 10 female respondents on their 72 pregnancies. The minimum number of pregnancies a woman had was 6 and the maximum was 11. Less than half (34) of the pregnancies were wanted, 27 percent (19 pregnancies) were mistimed and 25 percent (18 pregnancies) were unwanted. Interestingly, less than half the pregnancies were wanted and more than half were reported as either mistimed or unwanted, which shows that on average every woman wanted just 3.4 children but due to either unmet need for family planning or method failure they actually had at least 6 pregnancies.

Desirability of pregnancies varies significantly by pregnancy order. For women, intentions to limit start with early pregnancies. For instance, $5 \%$ of the first two pregnancies were unwanted by women. However, men do not have such considerations, until much later parities. There is a sharp difference of wantedness between women and their husbands even in subsequent pregnancies: $10 \%$ of third and fourth pregnancies were unwanted by women and only $5 \%$ of men felt this way. A similar trend was observed for all order pregnancies. $35 \%$ percent of women and $15 \%$ percent of men reported the fifth and sixth pregnancy as unintended. After 6 pregnancies, intentions appear to converge: $100 \%$ of women regard more than six pregnancies as unwanted and the figure is $67 \%$ for men.

"I did not want this (first) pregnancy because I was too young to be pregnant but my husband and all other family members were very happy." (FIDI-07) 
Table 1: Number of un-intended" pregnancies as reported by women and men by pregnancy order

\begin{tabular}{rrrrr}
\hline Pregnancy order & $\begin{array}{r}\text { Un-intended by } \\
\text { women }\end{array}$ & $\begin{array}{r}\text { Un-intended by } \\
\text { men }\end{array}$ & $\begin{array}{r}\text { Total } \\
\text { Pregnancies }\end{array}$ \\
\hline $1-2$ & $5 \%(1)$ & $0 \%$ & $(0)$ & 20 \\
$3-4$ & $10 \%$ & $(2)$ & $5 \%(1)$ & 20 \\
$5-6$ & $35 \%(7)$ & $15 \%(3)$ & 20 \\
$7-8$ & $66 \%(6)$ & $33 \%(3)$ & 9 \\
$9+$ & $100 \%(3)$ & $67 \%(2)$ & 3 \\
Total & $25 \%(18)$ & $12.5 \%$ & $(9)$ & 72 \\
\hline
\end{tabular}

$*$ un-intended $=$ mistimed + unwanted

Women express their unwantedness of pregnancy from the second pregnancy, while husbands do so after the fourth pregnancy. Women are more concerned with social, financial and health issues related with childbearing and rearing. Early pregnancies (1-3) are declared as mistimed and later pregnancies (4 plus) convert into unwanted pregnancies. These transitions determine the strength of decisions. For example, for mistimed pregnancies, women either compromise with the situation (especially when husbands do not allow termination) or if they do not succeed in attempting termination.

Since the desirability of each pregnancy plays an important role in its outcome, respondents were asked about their own as well as their husbands' feelings at the time of conception and how it influenced the pregnancy outcome. Data presented in Table 2 suggest that when both wanted pregnancies, they almost always resulted in either a live birth or a spontaneous abortion. Nine pregnancies were reported as unwanted by wives: five of these pregnancies resulted in live births, one ended in an induced abortion and three pregnancies were reported as attempted but failed abortions. Sixteen of the pregnancies were reported as 'mistimed' by wives, two were aborted and two were failed attempts at an abortion. On the other hand, none of the three pregnancies reported as unwanted or mistimed by husbands only, ended in abortions.

This situation unfolds in three ways: (a) there are very few pregnancies, which are reported as unwanted by the husbands, (b) wives do not make any effort to terminate those pregnancies which are wanted by them, regardless of husbands' wishes, and (c) husbands are not generally in favour of induced abortion and they do not force their wives to have an abortion even if they consider a 
pregnancy as unwanted. All of these situations refer to women's stronger determination for fertility regulation. There was mutual consensus on pregnancies, which were unwanted by both husbands and wives, out of which only two pregnancies ended up in induced abortion and four were attempted abortions.

Table 2: Outcome of pregnancy by wantedness status by both spouses

\begin{tabular}{|c|c|c|c|c|c|c|}
\hline Desirability & $\begin{array}{l}\text { Live } \\
\text { Birth }\end{array}$ & $\begin{array}{r}\text { Still } \\
\text { Birth }\end{array}$ & $\begin{array}{r}\begin{array}{r}\text { Spontaneous } \\
\text { Abortion }\end{array} \\
\end{array}$ & $\begin{array}{r}\text { Induced } \\
\text { Abortion }\end{array}$ & $\begin{array}{r}\text { Attempted } \\
\text { Abortion }\end{array}$ & $\begin{array}{r}\text { Total } \\
\text { Pregnancies } \\
\end{array}$ \\
\hline Unwanted by both & 1 & 0 & 1 & 2 & 3 & 7 \\
\hline $\begin{array}{l}\text { Unwanted by wife } \\
\text { only }\end{array}$ & 5 & 0 & 0 & 1 & 3 & 9 \\
\hline $\begin{array}{l}\text { Unwanted by } \\
\text { husband only }\end{array}$ & 1 & 1 & 0 & 0 & 0 & 2 \\
\hline $\begin{array}{l}\text { Mistimed for wife } \\
\text { only }\end{array}$ & 12 & 0 & 0 & 2 & 2 & 16 \\
\hline $\begin{array}{l}\text { Mistimed for } \\
\text { husband only }\end{array}$ & 1 & 0 & 0 & 0 & 0 & 1 \\
\hline Mistimed for both & 8 & 0 & 1 & 0 & 1 & 10 \\
\hline Wanted by both & 22 & 1 & 4 & 0 & 0 & 27 \\
\hline Total & 50 & 2 & 6 & 5 & 9 & 72 \\
\hline
\end{tabular}

This shows that concurrence of intentions among couples does not necessarily lead to a successful abortion.

"I went to a doctor for an abortion but she refused. Then I decided to leave it as it was." (FIDI-06)

It is interesting to see the outcomes of pregnancies in the context of their wantedness. In case of unwanted pregnancies, women try to abort pregnancy by all means even if their husbands are not willing and they have to do it secretly. Most attempts at secret abortions are home-based remedies like women taking tablets or lifting weights. Such women cannot go for clinical procedures because of mobility and economic constraints. 



\section{Chapter 3: Factors underlying unwantedness of pregnancies}

An important question to be explored was why do women fail to translate their reproductive thoughts/wishes into reality? Ideally if women want to avoid the next pregnancy they must use some means to control their fertility. There are two main factors responsible for unintended pregnancies: the first is non-use of contraceptives and the second is failure of contraceptive methods during use.

\section{Non-use of Contraceptives}

Contraceptive methods were not used to prevent 55 of the 72 pregnancies. Women, who had unintended (mistimed or unwanted) pregnancies and did not use any contraceptives, described some important reasons and concerns about non-use.

\section{i) Perceived natural spacing}

One of the main reasons for non-use of contraceptives was women's perception that they are protected and they cannot get pregnant again because menstruation does not resume for some time. This period varies between one year to two years after delivery. Women assume they are protected on the basis of their previous experiences. One of the reasons for delay in resumption of menstruation is breastfeeding practice. During this perceived natural gap women often do not even think they need any family planning method and eventually become pregnant and then opt for an induced abortion. As one of the respondents describes her situation:

"I did not use any family planning method, I just breastfed my child and I did not get pregnant and I did not even menstruate during that time." (FIDI-01) 
'There is a gap of two and half years between all my children. My menstruation used to resume one year and eight months after the birth because I breastfed my children for this period." (FIDI-07)

\section{ii) Non-availability of FP services}

A major reason for non-use of contraceptives was either the lack of knowledge or the lack of availability of family planning services. Almost all of the women interviewed were middle-aged and reported that there were no family planning services available when they started childbearing. That is true because the Basic Health Unit (BHU) was established about 10 years ago and Lady Health Workers started working recently (since 2002). Establishment of a BHU does not mean that family planning services are available because initially BHUs did not provide family planning services.

Inconsistent use of family planning methods also contributes to occurrence of unwanted pregnancies. In one case, a woman was using injectables but in due course, injectables were out of stock at the BHU and she could not buy them from a private clinic because of her financial problems. Some respondents mentioned that they were using condoms regularly but just once they could not use it during intercourse. That one time resulted in pregnancy and therefore, they opted for induced abortion.

As is depicted in the case of Zeenat, who is a 41-year old woman, with five daughters and two sons and eight pregnancies. Her first pregnancy resulted in spontaneous abortion while the result of the rest of her seven pregnancies was live births. Mistimed pregnancies started from her third conception. She wanted to delay her next pregnancy but family planning services were not available in the community and her husband restricted her from going outside the village. She wanted to have just two children due to poor economic conditions.

"I did not want more children because of poverty. My husband did not have a job and we did not have any money. I wanted to have no more children because it was hard to rear them." (FIDI-04)

Non-availability of services acted as a barrier in her fertility control intentions: 
"At that time there was nothing available for family planning. A Dai lived here, and then she moved from here and I could not even take pills because I was not allowed to go out. I would have used something (contraceptives) if my family allowed me to go outside." (FIDI-04)

After having four children her desire to stop became strong but there was no means to use to limit fertility and eventually she produced seven children.

"Out of all my seven children, the last three daughters are entirely against my wishes." (FIDI-04)

She tried to terminate her fourth and eighth pregnancies but did not succeed.

"I got pregnant again when my daughter was 8 months old, then I took tablets (oral pills) for termination which were given by a Dai who was a friend of my mother-in-law. But I left using pills because I had severe dizziness while I had to take care of my two young children and there was also a heavy load of household chores." (FIDI-04)

\section{iii) Fear of side effects}

Each of the contraceptive methods has some characteristics that lead to discouragement in adopting methods. Selection of a method is clearly not a simple matter, because it involves a variety of drawbacks to find the method that is least objectionable (Bongaarts and Bruce, 1995). In Tret, a major reason for nonuse of contraceptives was fear of (experienced or perceived) side effects. The IUD was reported as a very harmful method. Out of three IUD users, two experienced severe complications with method. In addition to that, mostly women told us about their experiences with IUD use. Some of the respondents mentioned situations, which adversely affected their health or in one case caused the death of a young woman.

Zeenat did not want to have more than four children but she could not use any family planning method and ended up giving birth to seven children. An important reason for non-use of contraceptives was perceived severe side effects. A girl from her own family who used the IUD who had to face some side effects and after some time she died. Although there might be some other cause of her death but local women believed the use of IUD was responsible. This incident 
made Zeenat horrified of family planning methods in general and the IUD in particular.

"There was one of our relatives. She was very beautiful and young. She got an IUD insertion and after that she started swelling up and then she died. It became difficult to lift up her dead body. I don't know if her ring (IUD) moved to her heart or somewhere else in her body." (FIDI-04)

Fear of the side effects of contraceptives hinders women from using them not only because it involves physical and even financial cost for managing the side effects (Casterline, Sathar \& Haque, 2001).

"My husband does not want more children but he says that sterilization can be harmful for health and the other thing is, we heard that one of the children dies if a woman gets herself sterilized. It has happened here with two women. That is why I will never go for sterilization." (FIDI-08)

\section{iv) Husbands' opposition}

Pakistani women mostly believe that their husbands are against most of the contraceptive methods and using any method without the husband's approval is unthinkable (Population Council, 1997). For many married women, their husband's opposition is an important factor not to practice contraception, despite their own desire to do so (Bongaarts \& Bruce, 1995). The husbands of some of the respondents had rigid religious beliefs and were against family planning use. Non-use of contraceptives due to these problems ended up in mistimed or unwanted pregnancies, which resulted sometimes in giving up to the situation or having an induced abortion. (The communication and decision making process between spouses is discussed in detail in chapter 4).

\section{Method Failure}

Temporary contraceptive methods (condom, withdrawal and pills) have higher failure rates compared to clinical methods (Miller, P., A. Kayani and A. Minhas, 2000). About half of women reporting induced abortions became pregnant while using some contraception, predominantly condoms and withdrawal (Casterline, J. and S. Arif, 2003). Contraceptive methods were used to prevent 23 percent (16) 
of these pregnancies, but the method failed. The most common methods used were condom and withdrawal. In case of condom use, its rupture led to unintended pregnancy, while for withdrawal, improper use of the method resulted in pregnancy. Pills and IUDs were also used to prevent pregnancies and their failure was also reported in female focus group discussions.

Interestingly, despite high rates of failure of condoms, their use remained high due to fear of experienced or perceived side effects of other modern methods like pills, IUDs, injectables and sterilization. Women and their husbands sometimes prefer condoms even after experience of failure more than once. Two of the respondents got pregnant as a result of condom rupture twice, but despite that, they were still using condoms.

"Although I became pregnant twice again due to condom rupture, but I am still using this method because my body is already swollen and the IUD can harm me more; injectables and pills do not suit me and my husband does not allow sterilization." (FIDI-08)

"I already had the experience of condom rupture but my friend suggested to me to buy good quality condoms. We bought expensive condoms but just once it ruptured and I became pregnant again ...now we will not use condoms because of their failure twice." (FIDI-05) 



\section{Chapter 4: Contraception and abortion: experiences, communication and costs}

\section{Spousal Communication}

By and large, spousal communication regarding contraception and abortion is not very frequent in Pakistani culture. Men and women are supposed to demonstrate their fertility immediately after marriage because there is pressure from family and society. There is no trend of prior discussions or planning between husbands and wives about the number of children they would like to have in their lives and when to have them. Decisions are usually made after experiencing poor economic conditions, poor health conditions and child rearing problems. Women are more likely to realize and give importance to these issues, and as a solution they want to space or limit childbearing, while men are least concerned about such issues. This is the point when women raise this issue with their husbands and try to make them realize the intensity of their reproductive intentions. As a result, sometimes men agree to use contraceptives but sometimes they oppose them due to religious concerns, fear of side effects and fear of retribution. Due to this lack of communication and concurrence, women end up having more children than they desire, unless the divergence is somehow converted into convergence.

For women, the intensity of discussion about contraception is easier to handle than the decision about having an induced abortion. In this study there were no cases where husbands initiated contraceptive use. In all cases women took the initiative. This was obviously difficult since the husband's permission is usually required for the use of contraception. One of the respondents from a female focus group discussion stated:

"It is obvious that just the husband can decide about the use of any family planning method. Who else can do it? Just the husband can decide it." (FFGD -06) 
Very few were reported as cooperative husbands, who were convinced easily in favour of contraception, and who started using a method with mutual agreement. The majority of the husbands opposed contraception for religious reasons, fear of side effects, or simply because they wanted more children. In the presence of the husband's opposition it becomes difficult to use contraception, especially when family planning services are not available nearby, and since women's mobility is restricted. Women, whose intention to regulate fertility starts at two pregnancies earlier than their husbands, face an uphill task of negotiations.

The points around which women negotiate with their husbands to bring them around to understand and agree to contraception are poor economic conditions, their health concerns, children's health and child rearing issues. Women seem more concerned with these problems than their husbands.

"I asked him (my husband) to do something - use injections or abstinence - to prevent the next pregnancy, because our children are very young, I am also suffering from bad health, and there is no one who helps me in the household chores. But he was against these things (contraception) and also he just returned from Raiwind (a town where religious people get together annually for learning about preaching of Islam). However, when he looked at the children's poor condition, he allowed the use of contraceptives. I went to the hospital and got an IUD inserted." (FIDI-06)

Similarly, a woman from the focus group discussion tells us her own experience:

"I asked my husband to give permission for sterilization because I just wanted to have sterilization, nothing else, as there is no one to take care of my children and I had hundreds of other problems, so he agreed and gave me permission." (FFGD-03)

This convergence takes a long time and during the span of negotiations, and until a final agreement is reached, women have had to face one or more unintended pregnancies. Generally, husbands consented to use contraception towards much later parities. 
Women attempt to convince their husbands to agree to use contraception. But otherwise, women may try to use contraception without informing their husbands.

Women in the focus group discussion reported the possibility of secret use of contraceptives:

"Today it is no longer the trend that a woman is restricted to remain inside the house and she cannot go out. Now she can. Women do use injections and pills secretly. How can a man know that his wife has come home after getting an injection?" (FFGD-06)

But her decision about the secret use of contraception limits the choice of methods to just pills and injectables. In Tret both the hormonal methods were perceived as the most harmful for health, while for sterilization the husband's written consent is mandatory. For example, a woman just wanted to have two children but her husband was against family planning and therefore, she had to bear 7 children. After 6 pregnancies she went for sterilization secretly but she was refused and sent back from the hospital. Keeping in view these limitations, women sometimes used home remedies like taking liquid "neel" (whitener and shiner for white clothes), which is perceived as being effective for two years' spacing.

In the female group discussion, women discussed the reaction of their husbands if they used any contraception and their husbands came to know of it. Husbands could get annoyed and in the worst of situations they could beat their wives on secret use. However, after some time they agreed to the negotiations and sometimes sexual intercourse acted as a means of reaching agreement.

"Men are not so ignorant that they always beat their wives. They agreed (to use of contraceptives), but it depends on how the wife makes her husband understand." (FFGD-06)

Interestingly, the whole process from divergence to convergence relating to induced abortion is more or less the same as in contraceptive use. However, the main difference is the intensity of the discourse. As in the case of communication about contraceptive use, husbands and wives do not discuss induced abortion 
prior to the pregnancy being discovered. They give low importance to this possibility, whether or not they are using any family planning method. Nonusers are more prone to have unintended pregnancies, but even then they never plan how they might deal with the eventuality of a pregnancy if it occurs. On the other hand, contraceptive users never expect to conceive as a result of failure of a method and they do not discuss possible future actions because they think they are protected. This lack of communication is usually observed in initial cases, when couples have mistimed pregnancies, but after experiencing one or two unintended pregnancies they do discuss and decide whether to opt for induced abortion and where to go for it.

Spousal communication does not always end in concurrence, because wives cannot always convince husbands. Both partners may have different opinions with different intensity. This intensity of intentions can be measured by the actions taken by the respondents. Our interviews show that some respondents went for an induced abortion in the case of unintended (unwanted or mistimed) pregnancy. They were so committed to their feelings that they went against the social norms and even took the risk of health complications. In some of the cases where it was an unintended pregnancy for the woman but an intended one for the husband, the woman resorted to a clandestine induced abortion. Although the respondent knew her husband would get annoyed, and she expected the risk of physical violence or verbal abuse from him, but she did not care and still had an abortion. It demonstrates women's desperation in such situations.

"I did not tell my husband that I was going to abort this pregnancy. I took tablets from the local TBA secretly. When there was a lot of bleeding then my husband came to know that the pregnancy was aborted. I told my husband and he got annoyed." (FIDI-07)

In general, rural women are considered to be submissive, but here we noticed that some of the women were quite assertive. They did convince their husbands to support an induced abortion if there was initial disagreement between husband and wife, as can be seen in Nusrat's case.

"I was pregnant for two months when I got safai (DNC) from a lady doctor. I consulted her earlier and she said, 'come tomorrow and your 
problem would be solved.' I came home, discussed it with my husband and he said, 'don't do it, it may lead to a big problem, then what would we do?' but I did not agree and then he gave me money for an abortion." (FIDI-01)

Their actions to abort an unintended pregnancy also complemented the intensity of their feelings. Some of the women had made a number of attempts to abort unintended pregnancies. They explored different venues or tried different service providers for termination of pregnancy. For example, Firdos conceived as a result of condom rupture after having four sons and one daughter.

"We both (husband and wife) did not want more children because God had bestowed on us sons as well as a daughter." (FIDI-05)

But after conception they decided to abort the pregnancy. First she took herbal tea but nothing happened, then she went to a private clinic where the doctor gave her two capsules to regulate menstruation but this also did not have any effect, then she was given injections and capsules from another hospital but then:

"My problem could not be solved. I took those capsules too but could not succeed. I went for a urine test where they told me that my pregnancy was intact. I used so many ways but nothing happened so then we kept quiet as it was God's will." (FIDI-05)

It was hard to compromise with her pregnancy so she contacted a Dai to get a procedure as a last resort but even the Dai refused due to her poor health. Then finally she decided to continue the pregnancy.

\section{Public face and individual reality regarding contraceptive use and abortion}

A clear finding from this study is that people think and behave differently depending on the community versus individual level. The study found that people oppose induced abortion when they talk at community level but they accept it (willingly or unwillingly) when they have to face their own situation of an unwanted pregnancy. Then they justify it with their "helplessness". As reported in the female focus group discussions, although an induced abortion is not considered a good thing, women could abort their unwanted pregnancies when they are helpless and there is no other choice. 
"People are used to gossiping but we just concentrate on problems of our households. We should not care for others. We cannot control people's mouths. They just keep on talking about others but they don't know whether one has something to eat or has something to cover one's body or not. One should think with one's own mind and what we consider right is right." (FFGD-04)

It was also mentioned that women should be allowed to have an abortion for their unintended pregnancy if there is any genuine reason like a life-threatening condition for the woman, poor economic conditions, and very young children.

"Pregnancy should be terminated if there is a chance of the woman's death. Her life is more important than the pregnancy. She can get pregnant again but what would happen if she dies?" (FFGD-06)

"Termination is not good but it is okay if one is helpless. If one cannot afford clothes, shoes and other expenses of the existing children, then it is better to opt for an induced abortion." (FFGD-01,02,03,04 $\mathcal{E}$ 09)

Another woman from an in-depth interview justified her helplessness:

'When I had this pregnancy, I got upset. I thought that I already had too many children and could not produce any more children. I faced health problems during delivery, which used to be a very painful process. Births through C-section were not as painful as were normal vaginal deliveries. I thought, it would be easy to keep the child in the womb for 9 months but the delivery would very difficult. I already had three daughters and two sons. These were enough. I got upset because to rear such a large number was difficult. More children meant more problems. Children need education as well as good food. If I kept on producing children like this then the existing living children would have difficulties. I did not have much understanding about these issues before that is why I had so many. Then I opted for an induced abortion and prayed to God for forgiveness for the sin, which I had committed. I used to meditate and prayed for His forgiveness." (FIDI-03) 
Social unacceptability does not restrict women from having an induced abortion when they are determined. However, they are reluctant to disclose the outcomes publicly. Women who participated in the focus group discussions did not consider abortion an absolute taboo. In fact, they were of the view that if a woman is helpless and there is no other option, then she should not care about other people and should do whatever suits her.

"It is a common practice of people to talk about others. We should look at our own problems (majburian). We should not care about others, who should control their tongues." (FFGD-10)

\section{Comparative Costs of Contraception and Abortion}

In order to understand the trade-off between contraception and induced abortion, comparative views were investigated. In every case, the respondent considers contraception a better choice than pregnancy termination with many justifications, but the major justifications are costs. While making decisions about use of contraceptives or induced abortion, women weigh the costs and benefits of each of the options. There are financial costs, social costs and health costs involved in the choice between contraception and abortion. These findings supplement the results presented in the earlier, detailed research on abortion conducted by the Population Council (Population Council, 2004).

\section{i) Financial costs}

Both abortion and contraception choices translate into monetary terms. Men and women do compare the cost of each contraceptive with induced abortion. The respondents (both men and women) in selected communities said that contraceptives are less expensive than induced abortion. For example, oral pills and condoms are available at their doorsteps supplied by community health workers (Lady Health Workers) free of cost or for minimal and affordable price. That means there is no time wasted in getting these methods. Apart from availability of contraceptives from LHWs, contraceptive methods are also available at health outlets (Basic Health Units and private clinics) and grocery shops situated within the community. 
On the other hand, terminating a pregnancy is very expensive. Abortion providers charge a lot of money to carry out an abortion.

"Financial cost is the biggest issue for induced abortion. Doctors demand 4,000 to 5,000 rupees, so why we should not spend that money on child rearing instead of spending it on abortion? No one cares for you in case of any problem if you don't have money." (FFGD-08)

One of the female respondents, Batool Bibi, who already had four children with two young daughters, wanted no more children at all but as a result of failure of her FP method she decided to terminate that pregnancy She went to a private clinic in the nearby city where 1,500 rupees were demanded as charges to abort a two-month pregnancy. At that time she was unable to afford that price so she came home. In the fourth month of gestation she still could not adjust to having a pregnancy. She then went to her sister for advice; the sister talked to a service provider but this time the service provider asked for 12,000 rupees and that amount really forced her to continue the pregnancy.

"My sister said, you cannot abort this pregnancy because you would never be able to arrange this amount, so continue it and get yourself sterilized just after delivery." (FIDI-02)

Another woman expressed her feelings in the same context.

"When I had this pregnancy, I thought to abort it because I already had one son and four daughters - these were enough. My husband was retired from his job. Inflation is very high and it was too difficult to run the house. I thought to abort the pregnancy, but I consider that it is a great sin and why should I not use the money to be spent on it for my home. I remained silent and left it." (FIDI-10)

One of the other factors that make induced abortions more expensive are travel costs. Since safe abortion services are not available at community level, therefore, women have to travel to nearby cities. Also restricted or limited female mobility makes it more difficult for women to travel. On the other hand, family planning 
methods and related services are considered inexpensive and more accessible now.

"Now family planning is provided free of cost. A woman goes to the FP center where they charge just 20 rupees for IUD insertion. Pills are delivered free at our doorstep. Injectables and condoms are provided free. Now there are many facilities, every method is being provided free of cost. We never bought condoms because the health worker provides them at home. Obviously pregnancy termination is expensive in addition to its bad effects on health. Induced abortion has worse effects on health than bearing a child." (FIDI-08)

Couples prefer contraceptives because some of the methods protect women from pregnancy for a longer period. For example, the IUD and contraceptive surgery protect women for a longer period of time. On the other hand, women who had induced abortion are again exposed to the risk of pregnancy soon after the abortion.

"Family planning is better because with induced abortion one gets pregnant just after 2-3 months. Women also get many diseases with abortion." (FFGD-03)

This finding is somewhat different to what was found earlier (Population Council, 2004). One possible reason could be that some of the respondents in the earlier study terminated their pregnancy at clinics where abortions are terminated through MVAs, a much safer technique.

\section{ii) Social Costs}

Couples also take into account the social cost while making decisions regarding the means or actions to control fertility. One of the major hindrances to use induced abortion as a means of fertility control is its social unacceptability. People consider it a sin and bad practice in the religious context. Respondents in Tret were more reluctant to talk about induced abortion than contraceptives. The community perceives that women who go for induced abortion are morally corrupt. If they learn that someone has had an induced abortion, the community thinks that she did so because someone else is involved in her impregnation than her husband. 
"Women say that the woman would be carrying someone else's child rather than her husband's - that is why she terminated her pregnancy." (FFGD-03)

On the other hand, contraceptive use is more acceptable than induced abortions. People talk about use of contraceptives easily. They do not even hesitate in sharing their own experiences in this regard. Sometimes women take suggestions from other users because talking about family planning is more socially acceptable now than it was a decade earlier. But of all the methods, female sterilization does carry some social costs. For example, one of the male respondents (Abbasi) mentioned that female sterilization had led to the loss of at least one of their living children as "divine retribution". Therefore, he would never recommend contraceptive surgery. Although women also reported this it does not prevent high parity women from using this method to avoid further pregnancies.

These social costs of being stigmatized do not restrict women from induced abortion when they are determined but they do not disclose the outcomes publicly. Women who participated in the focus group discussions did not consider an abortion an absolute taboo. They were of the view that if a woman is helpless and there is no other option, then she should not care about other people and do whatever suits her.

"It is a common practice of people to talk about others. We should look at our own problems (majburian). We should not care about others, who should control their tongues." (FFGD-10)

\section{iii) Health costs}

Men and women do consider the health hazards of using contraceptives and induced abortion. They do compare health problems, which occur due to use of contraceptives and induced abortion. Respondents mentioned that use of contraceptives as well as induced abortion had health problems but health problems due to induced abortion were more severe than those due to contraceptives. Health problems due to contraceptive use are minor and manageable whereas induced abortion complications are life threatening and 
need referral to a well-equipped health facility. For example, heavy bleeding due to induced abortion puts women at risk of death. A few women who experienced induced abortions (safe or unsafe) mentioned that they would never go again for induced abortion because of health complications. As one of the respondents mentioned, she almost died due to abortion complications.

"Wasted the money, wasted the child and even lost my own health." (FFGD-04)

Another female respondent stated:

"It is easy to get pregnant, and easy to have a delivery but it is very difficult to rear children or have an induced abortion." (FFGD-04)

According to reported feelings, family planning sounds easy to use and relatively more affordable compared to an induced abortion from all aspects of costs. Respondents' inclination and level of satisfaction seems high towards family planning. The question then arises that if this is the case, why do men and women in Tret not use contraceptives and why do they opt for induced abortion (willingly or unwillingly) as a back up. The full analysis of the situation suggests that people have knowledge about contraception but as a society they do not accept it whole-heartedly. The major factors of non-use or irregular use of contraceptives are weak intentions and weak decisions. Religious concerns, husband's opposition, fear of perceived side effects, fear of retribution and accessibility problems determine their intentions and decisions. These constraints weaken their intention to use any method, so ultimately they have to face unintended pregnancies, which result in induced abortions.

The husband's opposition plays a very important role because all future strategies to deal with unintended pregnancy (contraceptive use) are formed after discussion with husbands. If a husband agrees to using contraceptives, then mutual decisions make the process easy because it involves the choice of method, where to get the method, financial cost and how to manage side effects. On the other hand, if husbands do not agree with wives then either women have to be able to use any method or to use a method on their own. The outcome then is 
that women have to manage all these issues alone. Such opposition from husbands weakens the intentions and decision making power of women.

"I did not want more children (after four) but what could I do. I was just helpless. Nothing was available here at that time; my dai had moved from here due to which I could not take pills (secretly from my husband) and my husband did not let me go out. I would have used any method if I were allowed to go outside the community." (FIDI-04)

\section{Induced abortion as an "alternative" or "backup" to contraception}

One of the objectives of the study was to learn whether induced abortion is being used as an alternative to contraception for fertility regulation or it is being used as backup for contraception. The terms "alternative" and "backup" are defined from the respondents' point of view. If the respondents mention that they were not using any family planning methods to avoid pregnancy, keeping in view the choice if pregnancy occurs, then they will go for termination if it is an alternative. Induced abortion was seen as a backup when women used a method but pregnancy occurred due to method failure, or respondents were not using any method by considering that period as safe.

Women in our study are generally practicing induced abortion as a backup for contraceptive methods (including failure) to regulate fertility. Almost all of the males as well as female respondents mentioned induced abortion as a backup for contraceptives or for use failure. 


\section{Chapter 5: Couple concurrence and discord regarding pregnancy wantedness}

Both husbands and wives were interviewed to collect information on each of their pregnancies to get male and female perspectives regarding their intentions and concerns of conception and abortion. This section will try to explore how these spouses think about each of their pregnancies and to what extent their perceptions and feelings match.

Five married couples were interviewed for this study. Information was collected on a number of pregnancies, live births, and spontaneous or induced abortion from both partners; and it was compared and the discrepancies were identified.

Table 4: Convergence and divergence of couples on some selected issues

\begin{tabular}{lccr}
\hline Category of questions & Convergence & Divergence & $\begin{array}{r}\text { Total } \\
\text { couples }\end{array}$ \\
\hline Pregnancies & 3 & 2 & 5 \\
Live births & 5 & 0 & 5 \\
Spontaneous abortion & 1 & 4 & 5 \\
Induced abortion & 1 & 4 & 5 \\
Attempted but unsuccessful & 2 & 3 & 5 \\
abortion & & & \\
Age of the youngest child & 2 & 2 & 5 \\
Desire for more children & 5 & 0 & 5 \\
\hline
\end{tabular}

Three out of five couples reported a similar number of pregnancies. However, there was a discrepancy in the reported number of pregnancies of two of the couples. One husband reported three pregnancies fewer and another husband reported one pregnancy more than his wife. The husband who reported fewer pregnancies than his wife did not report some of the pregnancies, which resulted in spontaneous or induced abortion. Although he mentioned two spontaneous abortions, he missed the third pregnancy and did not report the induced abortion at all.

"Perhaps one or two pregnancies got wasted spontaneously initially and then we got daughters by the grace of God... it never happened that we 
aborted any of our pregnancies intentionally." (MIDI-05, husband of FIDI-01)

The respondent might not consider it important to discuss wasted pregnancies or he did not know about the induced abortion his wife had had or he did not want to disclose an induced abortion. There are more chances of the last option because his wife mentioned that her husband had tried to stop her from an abortion procedure but she did not agree and finally her husband had provided the cash for the abortion.

"I aborted that pregnancy through a nearby doctor. First I went to discuss with her then she asked me to come next day for termination of pregnancy. I came back and discussed with my husband, he asked me not to do it because it may lead to complications then how would we manage that but I did not agree with him and then he gave me the money." (FIDI01, wife of MIDI-05)

This woman started facing severe complications just after the procedure and at that time she called her husband who took her home from the service outlet by hiring a vehicle.

"The doctor used some instruments inside my uterus but she could not take anything out of it rather she inserted an IUD, and my pains started right from her clinic. My younger daughter was with me, I asked her to call my husband. He came and he cursed me first and then hired a van to take me home." (FIDI-01, wife of MIDI-05)

The other husband reported two pregnancies, which resulted in induced abortion, but his wife did not report these. She reported two of her pregnancies as attempted abortions, which were unsuccessful and resulted in live births. This is how she describes her attempt to abort her second unintended pregnancy:

"For termination of my last pregnancy I used family planning tablets from the hospital (BHU).The lady health worker is our relative, she gave me those tablets but I could not use the tablets regularly. That is why the pregnancy could not be aborted. Someone also told me to have eggs with turmeric, I did, but nothing happened and then I thought to continue it." (FIDI-04, wife of MIDI- 03) 
On the other hand, the husband mentioned two induced abortions after the birth of the youngest child although he did not give details of these abortions.

"Yes it happened one or two times...I think two times that my wife got pregnant after my youngest daughter, then she used tablets and she became okay (pregnancy got terminated)." (MIDI-03, husband of FIDI04)

This discrepancy demonstrates that at times men can and do report induced abortions more accurately while wives, for whatever reason, may suppress information around induced abortions.

There was convergence between spouses in the reported number of live births. However, partners vary in reporting induced as well as spontaneous abortions. Four out of five husbands reported a different number of induced abortions as well as spontaneous abortions compared to their respective wives.

Out of four 'matched' couples, three husbands reported fewer spontaneous abortions than their wives. The main reason could be that they did not know about those pregnancies, which aborted very early after conception or they did not remember these pregnancies. One husband reported more spontaneous abortions than his wife because his wife did not inform him that the pregnancy was aborted. She did not want to continue that pregnancy and she knew that her husband would not let her abort the pregnancy. After a successful clandestine abortion she told her husband that her pregnancy has been spontaneously aborted and she did not even know about that conception.

Fewer husbands reported induced abortions compared to their wives. The main reasons for under-reporting are: the wife did not inform her husband about her induced abortion and the husband had considered it a spontaneous abortion; the husband knew but did not want to disclose it to others (researchers); in another situation there could have been a recall problem also because it was observed that generally women gave detailed and sequential information about all their pregnancies while husbands could not recall details. Of course, underlying this is the fact that fertility related issues are considered as a female domain and men are less concerned with such issues. On the other hand, one of the husbands who reported more induced abortions than his wife said that both of them did 
not want the next pregnancy because the last child was too young. He then worked on inducing the abortion by buying cock's eggs, which were used by his wife, and the pregnancy ended.

"My youngest son was breast feeding when my wife's menstruation stopped. We thought that she could not get pregnant but she did. I brought cock's eggs and fed her and then her pregnancy got terminated." (MIDI-01)

According to this husband, the pregnancy was terminated with mutual understanding but the wife reported this induced abortion as spontaneous. She said that pregnancy was unintended by her but her husband wanted to have the next child and he brought those eggs without knowing the fact that it can cause an abortion. She ate the eggs and the pregnancy was aborted unintentionally.

"One day he brought some cock's eggs and asked me to cook and eat them. I did and then the bleeding started. I did not know that these are so hot that they can abort the pregnancy. My husband also did not know it...I was happy that the pregnancy has been aborted spontaneously but he said that he would never have brought these eggs home if he knew, because he did not want to terminate that pregnancy." (FIDI-08)

Another husband reported two pregnancies as ending in induced abortions, which the wife failed to report. She reported two of her pregnancies as attempted but unsuccessful abortions, which resulted in live births. The husband mentioned two induced abortions after the youngest child although he did not give details of these abortions. These discrepancies demonstrate large gray areas of communication about abortions among couples in Tret. It is an important insight for future work, which would need to focus and rely on answers, most probably from women, regarding the number of abortions. However, such an approach would still need to tackle the issue of under-reporting of abortions by wives to their husbands. Such women did not inform their husbands that they are trying something to abort the pregnancies and after unsuccessful attempts they compromised and had to continue their pregnancies. Their husbands remained uninformed about the 'attempts' because either they were against termination or they wanted to have more children. 
"I did not tell my husband that I am trying to abort the pregnancy otherwise he would have never permitted me to have an abortion because he wanted to have another son." (FIDI-02)

At the time of the interviews, there was no divergence found in the desire for more children in the future. Both partners of these particular couples did not want to have more children with no variation of concerns. Poor economic conditions, grown up children, large family size, sufficient children and poor health of husbands came up as major concerns from both wives and husbands. One of the respondents was a TB patient and he could not work continuously and most of his earnings had to be spent on his treatment, so he was unable to even meet the expenses of their existing children.

"If there is one earning hand and 8-10 people are there to be fed then it is really hard to meet the expenses of the whole family. Another reason is that our children are grown up and we feel embarrassment in another pregnancy as this is the time to think about their marriages." (MIDI-03)

"No, now I will never bear any more children. Only I can feel it because only that person feels the burn who suffers it. I have three daughters and one son. May they live long. I seek help from my sister or from my brother. I beg for money and clothes and then provide school fees of my children. My husband is suffering from T.B. He cannot work more than 2-3 days because after that he starts having fever." (FIDI-02)

"Now our elder son is 13 years old. It looks awkward to keep on bearing children when there are already grown up children. Now we have to be careful so that they could not get to hear such things." (MIDI-01) 



\section{Chapter 6: Conclusions}

In Pakistan, pregnancy out of wedlock is unacceptable, thus people only report those pregnancies which occur within marriage. Couples mostly have arranged marriages. There is almost no concept of husbands and wives discussing reproductive intentions before and even soon after marriage. There is almost universal convergence on having the first child soon after marriage. This is done because men want to prove their masculinity and women need to demonstrate their fertility. Therefore, the first child is always wanted.

There is a continuing communication gap between spouses. They do not talk about their fertility or about contraceptive use or induced abortion. Wives are concerned about their own and their children's health. However, husbands are quite distant and minimally interested in fertility regulation.

Though spouses fail to plan their fertility at the time of marriage, they do start thinking about it as they bear children. The main reasons for fertility regulation are financial concerns in rearing children. An interesting observation in this regard is that generally people never think about these concerns at the start of their reproductive lives, but keep on bearing children. After having more than four children they become aware of financial constraints, but by that time they already have had a large enough number of children. But even when couples do reach this point, not all of them limit their fertility by using contraceptives. In many instances, husbands do not allow women to use a family planning method, at other times women themselves fear side effects, and sometimes couples together face the failure of a method while using it, especially condoms. In this way they fail to manage their fertility and they have more than 5-6 children and cannot meet their basic needs.

Women are clearly in favour of using contraceptive methods to achieve their reproductive goals. However, they cite non-availability of effective contraceptive methods at the community level and fear of side effects when they fail to use them regularly. In many instances they rely on temporary methods like condoms 
and withdrawal, which frequently end in an unwanted pregnancy. Women also become pregnant because they have unprotected sex when they assume they are protected. Most couples have the misperception that women cannot get pregnant after birth for a specific period (ranging from 12 to 30 months). However, many of the unintended pregnancies occur due to this misperception. At other times, the reason for an unwanted pregnancy is the casual and perhaps callous attitude of husbands in buying contraceptives, and the lack of segregated women's mobility and autonomy.

Higher order pregnancies are more likely to be reported as unintended. Mistimed pregnancies start earlier and unwanted pregnancies start later into childbearing. More importantly, women's unintended pregnancies start much earlier. They are usually two pregnancies ahead in time, as compared to their husbands, in classifying a pregnancy as unintended.

Women tend to compromise with a mistimed pregnancy and usually carry it to full term. However, they seem to be more likely to seek an abortion in the case of an unwanted pregnancy or at least express it in those terms. They try all available means of induced abortion, starting with home remedies (like jumping, lifting heavy loads, etc.) to going to service providers. Some women are so desperate that they convince their husbands to allow them to have an induced abortion, while others go clandestinely. They usually end up with an unsafe abortion, which results in severe health problems. Women who seek an induced abortion secretly, expect some verbal as well as physical violence from husbands. However, the outcome is rarely the break up of a marriage. Women appear to accept this outcome because rearing an extra child is more difficult. When women face health complications, they are reluctant to go for an induced abortion again.

By and large, men do not approve of contraceptives, nor of induced abortions. However, when it comes to their own personal life, then they show some leniency and expediency in making decisions on the basis of their own existing situation. Essentially, they oppose contraception and induced abortion in public, but allow both, if done with confidentiality. 
As a consequence, men generally either do not report induced abortions at all, or report induced abortions as spontaneous abortions, also called "miscarriages". There are reasons for this under-reporting: either men do not know about the occurrence of that pregnancy which results in an induced abortion, or they do not know the exact outcome of the pregnancy (induced or spontaneous), or they possibly do not want to disclose it publicly. On the other hand, women generally report more accurately on the outcome of a pregnancy. Seeking information in chronological order about each pregnancy helps women in recalling events associated with each one.

The study found that induced abortion is being used as a backup for contraception to control fertility in Tret. Women opt for induced abortion when their unintended pregnancy is due to either method failure or misconception about the safe period. Men in general and women in particular prefer to use family planning methods to regulate fertility because they are less expensive, socially acceptable and easier to obtain, compared to induced abortion. However, their determination to use contraception increases towards the end of childbearing when there is no desire for more children.

Many of the women either did not use any FP method earlier for spacing or experienced method failure, due to which they had to face a mistimed or an unwanted pregnancy. One of the main reasons for non-use is non-availability of family planning services at that time. [That is true because the Basic Health Unit (BHU) was established in Tret about 10 years ago] and Lady Health Workers started working recently (since 2002). And also the establishment of a BHU does not mean that family planning services are available. Initially the BHU did not provide family planning services.

This study goes further than previous research in the Pakistani context to probe the extent to which each of these factors play a role and their relative strength in a setting which is fairly adequately served in terms of reproductive health services, lying in between typical urban and rural areas. The final explanation for the choice between abortion and contraception is a myriad of reasons ranging from availability and acceptability of services at the community level, to the most intimate of relations between men and women, to individual variation among 
women themselves relating to their own determination, autonomy and sometimes desperation.

In a setting such as Tret, certainly an improvement in the array of services for family planning and for reducing the outcomes of unsafe abortion (through better post abortion care and other safer procedures) would certainly improve the lives of men and particularly women in terms of health and well being. But more thinking and action is required to tackle the difficult areas of interspousal communication, women's power in relationships in settings where women are generally uneducated and constrained in terms of choices, economic power and especially in their mobility. While none of these areas represents an insurmountable obstacle, they do pose more of a challenge than the very first step, which should be addressed by the provision of more and better services all over Pakistan, but especially in rural areas such as Tret. 


\section{References}

Bongaarts, J., and J. Bruce,, 1995. “The Causes of Unmet Need for Contraception and the Social Content of Services", Studies in Family Planning; 26[2]: 57-75

Casterline, J. and S. Arif, 2003. “Dealing with unwanted pregnancies: Insights from interviews with women", Research report no. 19, Population Council, Pakistan

Casterline, J and S. W. Sinding, 2000. “Unmet Need for Family Planning in Developing Countries and Implications for Population Policy", Population and Development Review, .26[4]: 691-723

Casterline, J., Z. Sathar, and Minhaj-ul-Haque, 2001. “Obstacles to Contraceptive use in Pakistan: A case study in Punjab", Studies in Family Planning; 32 [2]: 95-110

Hakim, A., M. Sultan, Fateh. Uddin, 2001. Pakistan Reproductive Health and Family Planning Survey 2000-2001: Preliminary Report. Islamabad: National Institute of Population Studies

Miller, P., A. Kiyani, and A. Arshad, 2000. “On the dynamics of contraceptive use in Pakistan", Conference proceedings, Population Association of Pakistan

Population Council, 2004. Unwanted pregnancy and post-abortion complications in Pakistan: Findings from a national study. Islamabad: Population Council

Population Council, 1997. "The Gap between Reproductive Intentions and Behaviour: A Study of Punjabi Men and Women". Islamabad: Population Council

WHO, 2004. Unsafe abortion: global and regional estimates of incidence of unsafe abortion and associated mortality in 2000. $4^{\text {th }}$ edition, Geneva: World Health Organization. 



\section{Appendix A: Summaries of male and female in-depth interviews}

\section{1) Female In-depth Interview Summary \# 01}

Nusrat Bibi is a 50-year-old illiterate woman who conceived 11 times during her marital life, giving birth to 3 daughters and 4 sons. She has also experienced 3 spontaneous abortions and one pregnancy which was terminated intentionally. Nusrat got married at 16. Although initially she never thought about the number of children she should have, after three living children, she wanted to space her pregnancies so that her children would be able to take care of themselves. But she and her husband never used contraception because they considered it against Islam.

Thus, Nusrat Bibi kept on conceiving every ten months after her previous delivery. She had 06 living children, three daughters and three sons when she became pregnant for the tenth time. She did not want to continue that pregnancy, but she did not share her intention with her husband or any one else and she started taking a lot of aspirin tablets without consulting anyone, in order to terminate her pregnancy quietly.

"My son was too young - that's why I took aspirin tablets, thinking that the pregnancy may be aborted, but nothing happened."

After failure of this attempt to abort her pregnancy she went to a local doctor who agreed to abort her pregnancy. She then came back and discussed this with her husband who was initially not willing to seek an abortion, but then he gave money to her. The local doctor could not terminate her pregnancy safely and she had to face a lot of serious complications.

"I don't know what the doctor did. She inserted some instrument and, used some machines, but she could not take out anything and instead inserted an IUD. I started having pain there and then. My daughter was with me, I asked her to call my husband. He came and first he cursed me and then hired a van to take me home." 
She was taken to a city hospital in a very critical condition, where she was kept under treatment for a few days and she had to go through a DNC again. She was suffering from internal problems since then.

After that she did not use any contraceptives due to fear of the previous experience of her induced abortion and three years after the abortion she again got pregnant. Although she did not want to have any more children, she had the fear in her mind that termination leads to many health problems and this was linked with "shirk" (going against God's will).

After her seventh child she wanted to stop childbearing at any cost due to the family's poor economic situation. She finally decided: "and then I went for sterilization so that I could finally get rid of child bearing."

\section{2) Female In-depth Interview Summary \# 02}

Batool Bibi has three daughters and one son. She belongs to a very poor family where it is hard to even feed the children. Her husband is a T.B patient, and his doctor advised rest during the 9 months of the treatment but he cannot follow the doctor's advice because he has to earn to feed his children. His health problem gets more severe when he continuously does waged labour for 2-3 days.

Batool got married at the age of 14 and her first two pregnancies were mistimed for her, while her husband wanted to have more and more children. She did not want to be pregnant at such an early age and her desired gap was 4-5 years.

"I did not feel good because I was too young. I wanted to have children later because I was afraid that I could not take care of my children."

At that time she did not know any means to use for spacing so despite her desire, she had back-to-back pregnancies. Both of her first two pregnancies resulted in live births of sons but they died after some time. Even after the deaths of her two sons she did not want the next child too soon and she convinced her husband to use the withdrawal method for spacing. She also had irregular menstrual problem which she perceived a result of her of obsession, then she got her 
menstrual problem treated because her husband demanded a child. She then delivered two daughters with a gap of 1-1/2 years and then she made her husband agree to use withdrawal again although he wanted more and more children. He used withdrawal for one year but then left it because he thought she could not get pregnant until she had the treatment for her menstrual problem, but Batool became pregnant and was unhappy. She did not share the news with her husband and took a number of "Brufen tablets" for two days and additionally she started lifting heavy weights.

"I took eight Brufen tablets one day and 8 tablets the next day. I lifted more weights intentionally so that my pregnancy could be terminated. We normally fetch water from a distance but in those days I fetched more buckets. Eventually my pregnancy got aborted after twenty days. I knew that I tried for an abortion but I did not want others to know about my pregnancy that's why I asked my family members, 'what is this?' They said, 'you were pregnant but it has been aborted now'. I was basically happy. I did not inform my husband either about my pregnancy or the termination."

After that she had one son and one more daughter. Now she had three daughters and one son. That was the time when Batool decided to stop childbearing because her daughters were grown up although her husband wanted another son to make a pair. She got an IUD inserted just after her fifth child so that she could be protected for a longer time. After three years her IUD moved inside the body. She had to get it expelled from a tertiary level hospital after several visits. Just after that she had another unwanted pregnancy. She was determined to terminate it because of her economic condition. She then contacted a local service provider who demanded 1500 rupees, but as Batool was not able to afford that sum, she requested some concession but in vain.

"I asked the doctor to abort the pregnancy, at first she said that she also had children so she could not do it because I had just one son and who would be responsible if something happened to him. I got worried but even then I persuaded her for a termination and said 'I don't need this pregnancy because when one of my children gets something to eat the others remain hungry. We are very poor; the earthquake has damaged my house. Sometimes I go to my brother and next to my sister to beg for some 
money because my husband is ill, but even then you are demanding 1500 rupees. How I can manage this amount? Then, I came home and I spent 4 months thinking about it."

Till the fourth month of gestation she could not accept her pregnancy. She went to her sister, who talked to the service provider, but this time the service provider asked for over 12,000 rupees and that huge amount really forced her to continue the pregnancy.

"My sister talked to a doctor of a private clinic who demanded Rs. 12,000 $-15,000$ and finally it was settled at 12,000 rupees. She told me when I went to her, 'you would never be able to manage this amount so you cannot abort your pregnancy. Now you continue it and have a sterilization just after your delivery'. So I retuned home and did nothing else."

Now she is 6 months pregnant and she remains depressed all the time, but for the future she is determined to have a sterilization done as soon as she delivers because she does not want to take any more risks of pregnancy.

"I would never let it happen (next pregnancy) in any case. This is what I know because one who bears the burnt can realize the intensity. It does not matter even if I would have to argue or quarrel with my husband, but I would not let myself become pregnant again."

\section{3) Female In-depth Interview Summary \# 03}

Rehana experienced six pregnancies in her life, out of which one pregnancy ended in a spontaneous abortion and she terminated one pregnancy herself. She now has three daughters and one son.

Both husband and wife wanted their first pregnancy but she had a spontaneous abortion. Then she started her second pregnancy within a month, which resulted in the live birth of twin daughters. After that she became pregnant for the third time after a gap of $1 \frac{1}{2}$ years and delivered a son. 
She never used any FP method for spacing and the gap took place partially due to breast-feeding. When they had five living children, she and her husband decided to stop. But since they were not using any method to prevent pregnancy, she became pregnant four years later. Now they were worried because the high cost of rearing children was another factor in their not wanting any more children.

"I have three daughters and two sons which is enough, many more children cannot be cared. There are many problems related with children because we have to educate them and their food should also be good and if I keep on producing children then there would be problems for them in future. It is easy to keep a baby in my womb for nine months but it is hard to deliver the child and even harder to rear children."

Keeping in view all of these concerns she contacted a nurse for termination; she inserted a tablet and performed a DNC. She got the pregnancy terminated and after that she repented thinking that she had sinned.

"I asked for forgiveness from Allah that I have committed a mistake and a sin so forgive me. I used to say my prayers and fast to ask forgiveness of God."

Now 2-3 years have passed and they are using condoms to prevent any further pregnancies.

\section{4) Female In-depth Interview Summary \# 04}

Zeenat Bibi is 41 years of age. She has had a total of eight pregnancies. She has five sons and two daughters. One of her pregnancies resulted in a spontaneous abortion, while she attempted to abort two unintended pregnancies but could not succeed.

Zeenat got married at age of 17 . She said if she had some knowledge about family planning methods, she would not have had more than two children. After her marriage, her husband and mother-in-law did not let her go out alone and 
they were against family planning, she and her husband never used any contraceptives.

Her first pregnancy aborted spontaneously, and she had a daughter from her second pregnancy. After that she did not want to have another pregnancy soon. But she could not use any family planning method:

"I thought that I have a daughter, now I am free and I should conceive after an interval. But I got pregnant within three months. I did not want to be pregnant so soon because of our poor economic conditions. My husband did not do any work and we did not have any money, thus I used to say that this one daughter is enough and I don't need more children because it is hard to rear children in such poverty, but my husband desired a son."

After the birth of her second daughter she got pregnant again. She used oral pills to abort the pregnancy, which were given by a Dai (a friend of her mother-inlaw). Those pills did not terminate the pregnancy.

"She gave me family planning tablets and asked me to use them for a whole month for termination. I started but could not complete the whole month because I started having dizziness and I could not even stand. I felt it was dark everywhere all the time. We had a katcha house and my children were too young so there was a heavy workload that's why I could not continue it and the pregnancy could not be terminated."

She gave birth to a son from that pregnancy. She conceived again for the fifth time after sixteen months. She could not use any family planning method between the fourth and fifth pregnancies because (a) the dai had moved from there and (b) her husband wanted another son and he was against family planning. He was against it because one of his relatives used an IUD and after that she started getting swelling and eventually she died.

"There was one of my husband's relatives. She was young and beautiful . She had an IUD insertion and after that she started getting swollen and then she died. It even became difficult to lift up her dead body. I don't know if her ring (IUD) moved to her heart or somewhere else in her body." 
Her mother-in-law was also against family planning and she said to her: "why do you interfere in God's will? He does not bless some people with any children then why do you want to stop if He is giving you children". Her husband used to say: "we can afford all expenses, so what is wrong with you to bearing more children?"

By this time, she had two sons and two daughters and she wanted no more children. "Of all my seven children, the last three daughters are against my wishes."

The major cause of having three unwanted pregnancies was the non-availability of family planning services in Tret.

"I did not want more children but what I could do - I was just helpless. Nothing was available here at that time, the Dai had moved from here due to which I could not even take pills because my husband did not let me go out at all. I would have used any method if I were allowed to go out".

After the postpartum period of her fifth child ( $6^{\text {th }}$ pregnancy) she went for sterilization with her sister-in-law without informing her husband. But she was sent back because the husband's written consent is mandatory for sterilization. Again she could not use any family planning method although now her husband also did not want to have any more children. But he did not let her use any contraceptive.

"Now I repent - I would have used any method if it was available here."

Due to non-use of contraception, she became pregnant for the seventh time and a similar situation took her towards her $8^{\text {th }}$ pregnancy. She tried again to terminate the pregnancy through oral pills taken from a BHU but she could not use then regularly and this attempt was unsuccessful. Then she used some home remedy but nothing happened. She asked her husband if she could have an abortion but he did not agree. Other family members also opposed the idea of an abortion

"All of them frightened me by saying that an abortion is equal to seven murders and the mother is responsible for this murder."

At this point she resigned herself to the idea and decided to continue the pregnancy. As an outcome she gave birth to her seventh child. After that 
pregnancy she had an irregular menstrual problem. When she went to a hospital for sterilization, the nurses advised against it:

"You have deficiency of blood and the baby only grows with blood. That is why you will not conceive now. You don't need to use any family planning method now."

Now she believes she is safe from pregnancy and in case of another conception she is determined to get an abortion. "If I get pregnant again I know now that there are thousands of ways to get an abortion ". She is ready to abort even with financial constraints.

"There is a problem of money but it can be managed. I know ways of getting an abortion, which I did not know earlier. I would have just two children if I had knowledge about family planning and abortion methods."

She preferred family planning methods to abortion:

"Family planning is good for health but abortion harms it. Children can be reared easily with family planning and it is also cheap to afford while abortion is expensive."

\section{5) Female In-depth Interview Summary \# 05}

Firdos is a 30-year old woman living in Tret. She completed just three classes of education, and then she left her studies due to her mother's illness. She got married at the age of 14 to a man in her family and has gone through six pregnancies. She now has four living sons and two daughters.

Her first pregnancy resulted in the live birth of a daughter who died afterwards. After that she had four sons with a gap of $1-1 / 2$ to 2 years by using condoms. Her third pregnancy was unplanned and because her husband could not use a condom once due to its unavailability but she decided to continue her pregnancy because at that time she had just one son.

Her fourth pregnancy was also mistimed and unplanned as a result of method failure, i.e. condom rupture. 
"Something happened to the condom. Probably it got ruptured but we could not understand it. After conception I said that this method is also not effective."

She did not want to continue that pregnancy. Then she talked to her husband about an abortion but he did not agree, linking it with murder in religious context. Finally, she compromised and could not use even any herbal method for abortion at home because she had a stomach problem and was also diabetic. Thus she delivered her fourth son.

Both partners desired a daughter and so wanted her next pregnancy - so she gave birth as a result of her fifth pregnancy. Both husband and wife did not desire more children but being a diabetic, Firdos could not get sterilized. They started using condoms again postpartum. This time they bought imported condoms due to quality consciousness but after two years they experienced condom rupture again and she again conceived. That pregnancy brought feelings of unhappiness for both of them. At this point her husband dropped his religious objections, and got involved in efforts to seek termination of the pregnancy.

First he brought some herbs to be used in boiled form for termination, but nothing happened. At two months of gestational period she tried some capsules from a private clinic but that too did not work. Then she contacted another service provider, who gave her injections and capsules and assured her of a successful abortion. She kept waiting for her abortion but nothing happened:

\footnotetext{
"Yes I thought now it would have been aborted and I was waiting to get my periods then I again went for a urine test and the result was pregnancy positive. They told me that I was pregnant. I discussed it with a Dai, but she advised me not have an abortion because I was already very weak. I used various methods to terminate the pregnancy but everything was useless. Then we thought that it is the will of God so we both kept silent and accepted the situation."
}

She had to continue her pregnancy even after a number of attempts and she delivered a daughter three months ago. Now she is determined to get sterilized as soon as possible because she does not want to take any risk in future. She is 
not even concerned about her diabetes. She has obtained a promise from her husband that they would not have sexual relations until she gets sterilized. Her husband has permitted her sterilization and even for an induced abortion in case of another pregnancy.

\section{6) Female In-depth Interview Summary \# 06}

Bushra Khatoon is 29 years old and was 18 at her marriage. She completed eight years of schooling. She got pregnant for the first time after two months of marriage but she faced the problem of spotting up to 4-5 months of her pregnancy, for which she had been seeking treatment. She had a daughter from her first pregnancy. Her menstruation did not resume after delivery, when she got pregnant again. This time she was not happy with her pregnancy because her daughter was too young, but her husband perceived it as gift from God. She was again facing the problem of spotting and remembered that the doctor had told her in her last pregnancy that without seeking treatment for spotting her pregnancy could be aborted. She did not take treatment for spotting this time intentionally so that her pregnancy could be aborted in this way. She did not inform her husband about this plan. After some days severe bleeding started and her pregnancy was aborted naturally.

She fell very sick after her abortion, so her husband decided to use the withdrawal method, because the doctor advised her not to use an IUD. After one and a half years her husband stopped using this method because he wanted the next pregnancy. She did not want a pregnancy at that time and she started spotting problem again. She did not consider an abortion this time because she had experienced very bad health after the earlier abortion. She continued the pregnancy and had a son.

After delivery her menstruation resumed after 7-8 months, but the couple did not use any family planning method and consequently she got pregnant again. This pregnancy was perceived as mistimed by both husband and wife. She again planned to terminate the pregnancy by not treating the spotting problem but this time she did not face a spotting problem. She went to a local doctor and asked for 
an abortion but she refused and said, "You already have faced problems with termination of pregnancy and you don't have many children so there is no need of abortion". She asked her husband, who also disagreed due to his religious beliefs:

"My husband belongs to a religious political party and he is against such things. I just wanted to abort the pregnancy because my son was too young and there was no one at home to take care of my children."

She had to continue the pregnancy and delivered a son. Then everyone was happy on having another son. After three months of her delivery she asked her husband to use a family planning method because the children were too young, her health was not good and there was no one else at home to take care of the children. Her husband was a religious person and did not want to use any method but he gave her permission when he saw the condition of the children, as were not being properly taken care of. Then she got an IUD inserted, which she removed after five years and conceived just after its removal. This time she again faced the spotting problem but delivered a son.

Bushra did not get her menstruation back for four months. After that she started spotting, she went to the doctor who did not discover her pregnancy, and she thought this spotting was the regular menstrual cycle. She then inserted an IUD for spacing, but the spotting problem could not be solved and she went again to the same doctor after 15 days who referred her to an Islamabad hospital. Doctors at that hospital did an ultrasound test and told her that she was pregnant since last four months but the fetus was not growing. They then did a procedure and aborted the pregnancy. She did not want any more children so she asked the doctor to place an IUD after the procedure. Now she is planning to have sterilization done. Her husband has agreed and she has also planned to abort the pregnancy if she conceives between the phase of IUD removal and going for sterilization. 


\section{7) Female In-depth Interview Summary \# 07}

Tahira Bibi is 39 years old. She was 14 at the time of her marriage. She has gone through a total of 6 pregnancies, of which she has two living sons and three living daughters while one of the pregnancies was terminated. Now she is sterilized.

She conceived just after marriage for the first time but she was not happy with that pregnancy because she was too young but her husband was very happy. She shared her unhappiness with her husband but he said:

"We do not know any treatment for delaying or aborting the pregnancy and it is good that Allah has decided to give us the blessing of a child."

She used to conceive the next pregnancy after one year and 8 months of her last delivery because she weaned the child after this period and her menstruation resumed then. She experienced this gap in almost all her pregnancies. She had a daughter from the first pregnancy. She was again unhappy at the second conception but her husband was very happy, expecting to have a son. Then she got pregnant for the third time and had a son.

She terminated her fourth pregnancy because she already had two sons and one daughter and she did not want to have another child at that time. She was pregnant for two months when she contacted a Dai who gave her one tablet to abort the pregnancy. She took that tablet and suffered pain for 2-3 days and then finally the bleeding started and her pregnancy was aborted. She did not inform her husband earlier but after an abortion she told hem and he got very annoyed.

She conceived for the fifth time just four months after the abortion. But this time she was happy because she had a sense of guilt on terminating the last pregnancy. Now she did not want any more children but they never used any family planning method and she got pregnant the sixth time. Although she did not want that pregnancy, she did nothing and continued it. They still do not use any family planning method: 
"We never used any method because my husband and I did not like these methods. My menstruation resumed after one year of the last pregnancy and then we went immediately and I got sterilize."

She perceives the use of family planning as better than having an induced an abortion:

"In my opinion family planning is good to use while an induced abortion is a sin and this is like we are interfering with God's will. I feel that my daughter fell ill because I terminated my pregnancy. My husband also feels that our daughter got sick as a punishment for the abortion."

\section{8) Female In-depth Interview Summary \# 08}

Gul Bano is 29 years old. She got married at the age of 18 . She has experienced a total of six pregnancies in her marriage and now she has three sons and one daughter. One of her pregnancies was aborted spontaneously, while one was aborted intentionally.

She conceived for the first time just after marriage and she and her husband were very happy because she was very weak and the women of his family had doubts about her fecundity. She had a son from her first pregnancy and after just 6 months she conceived again. She became upset because she had thought that she could not get pregnant so soon after delivery. None of her family members informed her about spacing. She was not aware of it herself because of her very young age. After conception she asked her husband if she could take some medicine to abort the pregnancy, even though her husband wanted that pregnancy. He wanted to have two sons, but she did not agree with him. Then she went to a lady doctor who prescribed two tablets to be used for termination of the pregnancy. She took the tablets but nothing happened. She tried again and her husband brought some iron tablets from a doctor and told her to use these tablets for termination. He did this intentionally because he wanted her to continue the pregnancy. She used the tablets for a few days and then visited the doctor again to find out the status. The doctor laughed and told her the truth. She also tried some herbal teas but nothing happened. She then accepted her situation. 
Gul discussed with her husband her desire to delay the next pregnancy. Her husband agreed because the children were too young and the youngest was breastfeeding. After delivery her husband started using condoms but after some time, a condom ruptured and she conceived again when the youngest child was just 8 months old. She wanted to abort the pregnancy but his family members opposed it and so she did not try anything. After some days her husband brought some cocks' eggs and she asked her to cook and eat then. After having those eggs she started bleeding and the pregnancy got aborted. According to her neither her husband nor she knew that this could lead to an abortion but she was very happy about it.

Her husband started using condoms again, together with withdrawal. They used these two methods for three years until the husband wanted the next pregnancy. But she did not want any more children. Her husband stopped using the FP methods and she conceived again, which resulted in the birth of her third son. She used oral pills but they did not suit her and she stopped using them. Her husband started using condoms but after one year he stopped using it because he wanted the next child. She conceived but resisted it. She went to a doctor who did an ultrasound and suggested. She continued her pregnancy because an abortion could lead to a life threatening condition for her. She tried some herbal extracts but did not succeed in aborting the pregnancy. She gave birth to a daughter but her husband was unhappy at having a daughter. Just after the delivery the doctor suggested to her husband to stop childbearing because her internal condition was not good and she should not bear more children.

Her husband understood the situation and started using condoms again, but one ruptured again and she conceived. This time her husband did not want the next pregnancy:

\section{"How would I take care of the children and what would I do with the} children if you do not survive?"

Then he took her to the doctor for an abortion. The doctor charged 1000 rupees and inserted some medicine inside the vagina. After five days, heavy bleeding started and the pregnancy was aborted. But $t$ her body got swollen. 
After that her husband got scared and started using both condoms and withdrawal. But he did not continue withdrawal and just concentrated on condom use.

Now she does not want more children and her husband also agrees:

"These children are enough. It is hard to meet our daily expenditures and my own health is not good. There would be more expenses with more children, expenses of their education and other things. We stopped child bearing keeping in mind these things."

They have been using condoms for the last six years. She does not want to use any other method like the IUD, because she has a fear of side-effects. Pills and injectables do not suit her and her husband does not allow her sterilization due to fear of retribution, such as the loss of one of the living children.

Gul has thought she should have an induced abortion in case of another unplanned pregnancy:

"Now I cannot bear more children in any situation. I got very sick during my last pregnancy and even could not get up from my bed. Who will feed my children, who will wash the clothes? I will have to face pain and problem just for 4-5 days with an induced abortion, but it would not be for a whole nine months in the case of a pregnancy."

She thinks that "Neither bearing more children nor an induced abortion are good thing" and a woman must use family planning methods if they suit her. Government Family planning services are available in Tret free of cost, while an abortion is expensive and it also damages the women's health.

"Terminating pregnancy is very expensive and the woman also has to face complications and health problems. Delivering a child does not affect the health as much as an induced an abortion."

Although an abortion is bad for the health, Gul says that women have to opt for it because of financial problems. She thinks that a woman sacrifices and compromises her health when she has an abortion because she has to weight it against the expenses of the child, who will be born otherwise. 
"This is not a business of one day, rather it is the responsibility of parents to fulfill their children's expenses. They have to think about the expenses of the child's whole life."

\section{9) Female In-depth Interview Summary \# 09}

Nasreen got married at the age of 18 and she has primary level schooling. Now she is 38 years old. She experienced a total of seven pregnancies in her marital life out of which she now has four living sons. Two of her daughters died after birth, while there was one stillbirth.

She got pregnant for the first time six months after her marriage and a daughter was delivered. But she died after seven days of birth. They did not use any family planning method and she got pregnant again six months after her last delivery. Both husband and wife wanted this pregnancy because they did not have any child. They had a son from that pregnancy. She conceived for the third time after 15 months. She did not want to be pregnant at that time but after conception she did not do anything to abort that pregnancy and another son was born. After one and half months of delivery she had an IUD insertion with her husband's consent. She could continue its use only for three years because her body was getting swollen and she had pinching pain from the IUD. After that they did not use any method because they wanted the next child then she conceived and after five years of her last living child she had a daughter. This daughter had Polio at birth and she could survive only two and half years and then she died. She again got an IUD insertion because she had heard of many side effects of methods like pills and injectables. She again started having problems one and half years after the IUD was inserted and she removed it. She became pregnant but she wanted that pregnancy because both of her sons were grown up by that time. She had her third son and he was just six months old when she got pregnant again. She did not want that pregnancy so soon:

"My youngest son was just six months old when I conceived again. We did not use any method because I did not even think that I could get pregnant so soon. I got very upset when I got to know about this pregnancy. I went to 2-3 lady doctors but they all refused and said that they did not abort pregnancies." 
She was very upset and went to her mother to seek help:

"My mother advised me not to have an abortion. She tried to make me fear God and asked me to continue the pregnancy. I said I would not survive because my health condition was very poor. She suggested continuing this time and using a FP method after the deliver."

One of her husband's friends told him about a Hakim who gave medicines for pregnancy termination. They went there and used the Hakim's medicine and some herbal tea but nothing happened, so she had to continue the pregnancy and her fourth son was born as an outcome.

She had an IUD inserted for the third time just after the postpartum period. Now she is again having side effects of the IUD so that is why she is planning that her husband will use condoms after its removal. She does not want to be sterilized due to fear of side effects. Now she does not want more children but she is not willing to abort the pregnancy in case of an unplanned conception because she perceives an abortion as a sin. She justifies her attempted abortion saying that her youngest child was too young and it was difficult to rear two young children. She perceives family planning as better than having an induced an abortion.

"I think, family planning is better because to terminate a pregnancy is very bad and a sinful act and even the departure of a soul would be a very difficult task (if one goes for induced an abortion)."

\section{0) Female In-depth Interview Summary \# 10}

Saeeda Begum is 35 years old, with four daughters and two sons. Her husband is a retired person and she works as a Dai. She was 15 years old at the time of her marriage. She conceived three years after her marriage and during this period she had to face a lot of pressure from her husband and in-laws. Her first pregnancy resulted in stillbirth because an untrained Dai assisted in delivering that pregnancy. The dai had given her injections and pushed her body, which resulted in stillbirth. After that her husband decided not to allow her to deliver at home by an unskilled person. All of her subsequent deliveries were conducted in a hospital. She had four daughters in succession and this became a point of humiliation and taunting for her. Her husband however, remained good to her. 
"Allah gave me four daughters in succession and people used to taunt me that there is no use of our property because we don't have any son and all our children are daughters. My husband is very nice, he said that children are gifts of God, that's why we feel happy, even if they are daughters."

For all of her pregnancies, she had a gap of lactation amenorrhea for a year. The couple did not use any FP method.

After having five living children she wanted to stop child bearing. For that purpose she used an IUD but she did know the reason why she conceived during its use. She was then intent to terminate that pregnancy. But she stopped because she thought it a sin with termination of pregnancy equal to a murder, so she continued her pregnancy with delivered another son. Just after the postpartum period she used an IUD again so that she would not conceive.

"My family is complete now and my husband has retired. It is hard to meet expenses because the inflation rate is high. It is better to spend money on my home expenses, which I would have to pay for an abortion and this is also a sin."

She is not in favor of terminating pregnancies ant that was the thing that stopped her doing induced an abortion.

\section{1) Male In-depth Interview Summary \# 01}

Abassi is 35 years of age and involved in the poultry business. He has four living children (three sons and a daughter, who is the youngest). The interval between the first, second and third birth was three years. The couple never used any contraceptives because it was their perception that they had natural spacing of three years between their previous children. However after the birth of the third child, Abassi's wife became pregnant twice in a short time interval of three months. Both the pregnancies were mistimed, and terminated by using local methods. The motivation for the termination of both pregnancies was that the last child was too young. These pregnancies were a result of misunderstanding about natural spacing. 
After two years, Abassi's wife became pregnant for the sixth time. This time his wife wanted a daughter but he wanted another son. After the birth of a daughter they did not want more children and the wife had an IUD inserted. He did not want her to be sterilized because he thinks:

"We should not get sterilization because one of the sons might die."

The reason Abassi does not want any more children now is because his older children are now grown up.

"My oldest son is thirteen years old. It does not look good to have more children when the existing children are grown up. Now we have to be careful with our children so that they do not get to know about any such thing."

\section{2) Male In-depth Interview Summary \# 02}

Mazhar is 40 years old. At the time of his marriage he was 18 . He has schooling up to three classes while his wife's education is four classes. His wife had her first pregnancy nine months after her marriage and a daughter was born, who died after three days. The second pregnancy occurred just after three months and a son was born. This pregnancy was wanted by both partners that is why they did not use any family planning method. His wife got pregnant again after one year and three months and they did not use any method to prevent this pregnancy. This fourth pregnancy resulted in the birth of another son. This son was three and half years old when his wife gave birth to a daughter who was affected by Polio and survive only for three years.

Now they wanted to space their births and so his wife had an IUD inserted. But she had to remove the IUD after two years due to side effects.

"My wife got an IUD after my daughter was born and she continued using it for two years then she used to complain of belly swelling and she removed it."

After removal of the IUD his wife became pregnant (sixth conception) but after nine months there was a stillbirth. After the stillbirth they started using 
condoms but one condom ruptured and his wife had an unwanted pregnancy. He and his wife did not want to continue this pregnancy. They got to know about the conception. One month after it happened, and started their efforts for abortion. First of all they went to the doctor who had conducted the previous deliveries and got some tablets to be used for termination, but nothing happened. Then they thought of having an abortion procedure but the doctor refused to do so because of religious and health concerns.

"The doctor knew my wife's internal condition and therefore she refused to do Safai (abortion procedure). She said that it is a sin, and abortion would also lead to many health complications."

Then one of his friends suggested a Hakim who gives medicines for abortions. They went to that Hakim who gave some powder and syrups and assured them of termination. But the pregnancy was not aborted. They accepted the situation and finally agreed to continue with the pregnancy. One and half years after the previous pregnancy, another son was born as a result of the seventh and last pregnancy.

Now the youngest child is four years old. Mazhar's wife got an IUD inserted just after the birth of the youngest child. But she faced side effects previously and again this time, due to which she had to remove the IUD. Now he is using condoms because he does not want to have more children at all due to his own ill health and financial concerns.

"I don't want more children because I remain sick. One of my sons suffered from jaundice and I had to get him treated. Before that my daughter had Polio and I had to get her treated. As a result I got allergy. I also have stones in my kidney. Whatever I earn is spent on my treatment. I wished to have just two children."

He does not want more children but his wife wanted a daughter. Now he has decided to get his wife sterilized although he considers this method a sin but he justifies it:

"It is true that it is a sin (sterilization) but on the other hand, it is also a sin if good food and education are not given to children." 


\section{3) Male In-depth Interview Summary \# 03}

Rehmat is 45 years old now and he was 23 at the time of his marriage. He has schooling up to 5 classes while his wife has completed four classes. He is a truck driver. His wife is 41 years old and was 19 at her marriage. They have seven living children, including 5 daughters and 2 sons.

His wife experienced a total of nine pregnancies in her marital life. Two of the pregnancies were aborted intentionally. His wife conceived for the first time after 9 months of marriage and a daughter was born as a result. Her second and third pregnancies occurred with gaps of 15 months and both resulted in live births of daughters. There were two sons from the fourth and fifth pregnancies. After that there were two daughters from next two pregnancies.

Now he has seven children and does not want any more children, due to his poor economic situation.

"I am already upset because it is very hard to meet the expenses if there is only one earning hand. I earn 100-150 rupees daily and it is difficult to meet the expenditures. My daughters have grown up now and this is the time for their marriages."

He could not use any method earlier due to lack of awareness but now one of his relatives is working as a Lady Health Worker in the village. She provides family planning information to married women.

He wanted to have a son from the seventh pregnancy but they had a daughter. His youngest daughter was 8 years old when his wife got pregnant again. This time the pregnancy was unwanted, so she terminated that pregnancy by taking some tablets. He never thought of using any family planning method and he never paid any attention. After the seventh pregnancy he started using condoms, one of which ruptured. His wife conceived and so there was another unwanted pregnancy. His wife terminated this.

Currently they are using condoms, which are being provided by the LHW of the area. They are again using condoms despite the previous rupture. They do not 
like any other method. Sterilization is not considered suitable for his wife because her wounds heal after a long time and there are side effects of this method too.

He has strong intentions to abort any other unwanted pregnancy in future. He does not want more children at all, because the daughters are grown up and he now has to arrange their marriages.

"Now my daughters are grown up and I am worried about their marriages. My total attention has been diverted to them. It is my duty to think about it."

\section{4) Male In-depth Interview Summary \# 04}

Rahim is 45 years old. He got married to a girl from his family and has had schooling up to seven classes. His wife has completed six classes. He was 22 years old at the time of his marriage and his wife was 18. He works as a daily laborer.

He has four daughters and one son. His first son was born nine months after marriage but died after two days. The second pregnancy occurred after nine months, which also resulted in the live birth of a son. But he also died after a few hours. The third pregnancy occurred after two years but resulted in stillbirth of a girl. His wife conceived for the fourth time after two years and they had a daughter. He and his wife did not use any family planning method during all these four pregnancies because they did not have any living children until then. After having a daughter he wanted to have a son and did not use any method. His wife became pregnant again after nine months. Although he wanted to have a son, another daughter was born from the fifth pregnancy.

"I had wished for a son but whatever God almighty gives, is a blessing."

They had a son from the sixth pregnancy, which occurred after 9 months of the previous one. His wife got pregnant again after 15 months for the seventh time, because they were not using any contraception. She gave birth to a third daughter. He did not use any family planning method and as a result his wife 
had an eighth pregnancy and delivered their fourth daughter just 15 days ago. Now he does not want any more children due to their poor economic conditions. He is a daily laborer and gets work rarely.

"What will we do with more children, as I am a poor man."

His wife also does not want to have more children. Since he wanted more sons, his wife tries to convince him:

"My wife says that these children are enough and God would have bestowed us with a son if He wanted to".

\section{5) Male In-depth Interview Summary \# 05}

Zafar is 54 years of age and his wife is 52 . He was 23 years old at his marriage while his wife was 18 . His wife became pregnant one year after the marriage and that pregnancy resulted in a spontaneous abortion. Both husband and wife wanted their next pregnancy soon and after 9 months she conceived again. A daughter was born.

"We neither had the awareness nor were the facilities available to control our family at that time. Another thing is that this number of children was in our fate and God had to bestow us with these children. Perhaps we could have had less children if we were aware of family planning".

Zafar's wife became pregnant six months later for the third time. She conceived for the fourth time nine months after the previous delivery and a son was born. Then after another six months his wife had her next (fifth) pregnancy and bore a daughter. Uptil then they never thought of spacing between children because of their lack of awareness and non-availability of services.

"There were no services available and we did not even know about family planning. Television was also not common at that time and very few people had radios. Now there is a TV in every house and advertisements of family planning come after every 4-5 minutes. This trend was not common earlier."

His wife conceived for the sixth time after just six months. They had a son. According to him they could never think of having fewer children. His wife 
conceived for the seventh time after a gap of 15 months and after the delivery they thought of stopping childbearing.

"After the birth of this son (from $7^{\text {th }}$ the pregnancy) we became conscious and by that time facilities were also available easily. So my wife got her sterilization".

They heard about sterilization from their neighbours and decided to have it done. One of their neighbours got sterilized and they got motivated by her.

"We were able to think about sterilization when one or two of our neighbours had it. We felt shy but we also went to have it."

Zafar said that they would have fewer numbers of children if they were in this present era. Now he idealizes having three children due to economic reasons.

\section{6) Male In-depth Interview Summary \# 06}

Fida is 28 years right now and was 21 at the time of his marriage. His wife is 29 years and was 22 when she got married. Both have completed their middle level education. They live in a joint family.

His wife has experienced a total of five pregnancies so far. They have two living daughters and one son while one son died after 17 days of his birth. His wife became pregnant for the first time three months after marriage and they had a daughter. After that they wanted their next pregnancy soon to have a son. The son survived for just 17 days. They did not use any family planning method because they wanted another son very soon. Then Fida's wife became pregnant for the fourth time and a son was born.

The couple did not use any method even after having a son although they wanted to delay the next pregnancy. His wife conceived once again just two months after her last delivery. She took some tablets and her pregnancy was terminated. His wife talked about her intentions to one of their neighbours who gave her the tablets, which she used and nor Fida or his wife know the name of the tablets. This neighbour brought these very expensive tablets from her family doctor. 
"My wife was very weak and my son was too young. He was just two months old at that time, so we decided to seek an abortion."

The couple discussed and decided mutually and they did not inform any other family member due to fear of being stigmatized. They are not using any family planning method because he has a fear of side effects of these contraceptives.

"Use of condoms can lead to hundreds of health problems, like it can lead to internal infection and many other problems can happen. I was told all these details by a local doctor."

Just after the abortion he bought an injectable contraceptive from a very good chemist shop but his wife refused to use it due to fear of side effects. Now he does not want more children, but his wife wants to have one more son.

"She says that my son is all alone and by having another son he could have a companion. Although I don't have any such desire, my wife's desire dominates."

Now he has planned for his wife to have a sterilization after having another child. They would not have more children after the next pregnancy. 


\section{7) Male In-depth Interview Summary \# 07}

Shahid is 25 years old. He has completed eight years of schooling and helps his father in running a grocery shop. He got married at the age of 20. This was an arranged marriage and his wife was his relative. His wife became pregnant soon after marriage and every one in the family was very happy. A son was born but he died a week after birth due to some health problems. His wife conceived for the second time ten months after the first birth. A healthy son was born.

The husband and wife decided to delay their next pregnancy for two years and started using condoms. They were using condoms regularly. They did not use a condom once during intercourse and as result his wife become pregnant seven months after the last birth. Shahid got upset and wanted to terminate this pregnancy. He shared his thoughts with his wife, but she refused to go for an abortion. She said that an abortions cause health complications. This mistimed pregnancy was carried to full term and another son was born.

Shahid wants a daughter, but after two years. He is using condoms because they do not have side effects. If his wife has another mistimed pregnancy, then he and his wife will take a joint decision about terminating the pregnancy. 


\section{Appendix B:}

\section{Guidelines for in-depth interviews}

\section{i) In-depth interviews with Women}

Format: Encourage "storytelling" about the relationship and pregnancy/birth In case of births, ask names, when appropriate, of each child.

Be receptive to expressions of uncertainty and ambivalence

Sample: Women with at least 4 living children

\section{Questions}

1. Tell me about your current marriage.

$\circ$ When and how you got married? Are you living together?

○ Who else lives in your house?

- Are you living together? With parents or other family members? How have you supported yourselves economically?

2. Tell me about your first intimate relationship.

- What were your feelings about this relationship? What were your partner's?

1. Did you become pregnant at any time during this (first intimate) relationship?

- How did you feel about the possibility of becoming pregnant at that time?

- Did you think you were capable of getting pregnant or that your partner could get you pregnant? How likely did you think you could get pregnant?

3A. IF BECAME PREGNANT: Tell me about this first pregnancy.

- How did you feel when you first learned about it?

○ How did your partner feel?

- IF WOMAN AND PARTNER HAD

PROBE FOR RESPONDENT'S

"PREPAREDNESS" FOR

BECOMING PREGNANT DURING

FIRST SEXUAL RELATIONSHIP

AND PERCEPTIONS OF

FECUNDITY. 
DIFFERENT EXPECTATIONS ABOUT GETTING PREGNANT AT THAT TIME:

How did you sort this out?

- What happened with the pregnancy? IF ENDED: How many weeks/months was the pregnancy when it ended?

- At the time, did you feel you were under any pressure to have or not have the child? If so, tell me about your feelings, where these pressures came from and how you resolved them.

4. Tell me about your other pregnancies.

○ How many children do you now have?

FOR EACH PREGNANCY:

- How did it happen that you became pregnant?

- How did you feel about having a child at the time you learned you were pregnant?

○ How did your partner feel?

- IF WOMAN AND PARTNER HAD DIFFERENT EXPECTATIONS ABOUT GETTING PREGNANT AT THAT TIME: How did you sort this out?

- What happened with the pregnancy?

- FOR ANY PREGNANCY THAT WAS ENDED: How many weeks/months was the pregnancy when it ended?

- At the time, did you feel you were under any pressure to have or not have the child? If so, tell me about your feelings and where these pressures came from and how you resolved them.

BETWEEN PREGNANCIES:

- Tell me about what you might have done to avoid becoming pregnant between PREGNANCY(i) AND PREGNANCY $(\mathrm{i}+1)$ ?
PROCEED PREGNANCY BY PREGNANCY, STARTING WITH THE FIRST AND ENDING WITH THE MOST RECENT. FOR EACH PREGNANCY ASCERTAIN WOMAN'S AGE AT THE TIME AND WHETHER IN THE SAME CONTINUING OR A NEW RELATIONSHIP. IF PREGNANCY IS NOW A CHILD, ASCERTAIN CHILD'S NAME AND CURRENT AGE.

PROBE WHETHER SHE WOULD INFORM HER PARTNER AND INVOLVE HIM (AND ANYONE ELSE) IN THE DECISION.

EXPLORE LONG INTERVALS BETWEEN RELATIONSHIPS/ BIRTHS.

PROBE EXTENSIVELY TO GET A CLEAR PICTURE OF WHAT THEY DID. 


\begin{tabular}{|c|c|}
\hline $\begin{array}{l}\text { Was it your idea or your partner's to do } \\
\text { this? }\end{array}$ & \\
\hline $\begin{array}{l}\text { 5. Over the course of your pregnancies, did } \\
\text { your perception of your ability to become } \\
\text { pregnant change over time? How? } \\
\text { If you did anything to avoid but still } \\
\text { experienced an unplanned pregnancy, did } \\
\text { your use of contraception afterward change? }\end{array}$ & \\
\hline $\begin{array}{l}\text { 6. Tell me about your future childbearing } \\
\text { plans. } \\
\text { O Would you like to have (more) children? IF } \\
\text { YES: How soon? How many more? } \\
\text { Tell me about whose opinion matters in } \\
\text { your plans or who might influence you. } \\
\text { IF NO MORE OR WANTS TO POSTPONE: } \\
\text { What are you and/or your partner doing to } \\
\text { avoid getting pregnant? } \\
\text { IF NO MORE OR WANTS TO POSTPONE, } \\
\text { BUT DOING NOTHING: } \\
\text { You said you don't want your partner to get } \\
\text { pregnant now, but you aren't doing anything to } \\
\text { avoid pregnancy. Why not? } \\
\text { IF NO MORE OR WANTS TO POSTPONE: } \\
\text { If you were now to become pregnant, what } \\
\text { would you do? Whom would you involve in } \\
\text { your decision? Would you consider ending the } \\
\text { pregnancy? Why or why not? }\end{array}$ & $\begin{array}{l}\text { THIS DISCUSSION IS CRITICAL: } \\
\text { PROBE IN DEPTH } \\
\text { FACTORS AFFECTING DESIRE? } \\
\text { CONVICTION VS. AMBIVALENCE } \\
\text { INTENSITY OF DESIRE } \\
\text { PREGNANCY AVOIDANCE } \\
\text { METHODS/TECHNIQUES BEING } \\
\text { USED? } \\
\text { FOR HOW LONG? } \\
\text { SOURCE OF INFORMATION AND } \\
\text { SUPPLIES } \\
\text { PROBE ACTIONS THAT WOULD } \\
\text { BE TAKEN. } \\
\text { PROBE WHETHER SHE WOULD } \\
\text { INFORM HER PARTNER AND } \\
\text { INVOLVE HIM (AND ANYONE } \\
\text { ELSE) IN THE DECISION. }\end{array}$ \\
\hline IF NOT COVERED BY EARLIER DISCUSSION: & \\
\hline $\begin{array}{l}\text { 7. Have you and your partner ever tried to } \\
\text { plan when your pregnancy happened? Tell } \\
\text { me how you went about it. } \\
\text { Did you ever have an unplanned } \\
\text { pregnancy? }\end{array}$ & $\begin{array}{l}\text { PROBE THE CIRCUMSTANCES, } \\
\text { AND HOW THE WOMAN FELT } \\
\text { AND HER PARTNER'S ROLE. } \\
\text { PROBE HER PERCEPTIONS OF } \\
\text { PARTNER'S FEELINGS AND } \\
\text { WHETHER/HOW SHE WOULD }\end{array}$ \\
\hline
\end{tabular}


Have there been pregnancies that did not lead to a live birth?

How did you feel? How did you decide what to do? What informed your decision?

How did you feel about avoiding an unexpected pregnancy as compared to finding a way to end an unexpected pregnancy?
INFORM HIM OF UNPLANNED PREGNANCY.

IF NOT ALREADY CLEAR, PROBE ON HOW SHE VIEWS

PREGNANCY

PREVENTION/CONTRACEPTION

RELATIVE TO ENDING

PREGNANCY/ABORTION. 


\section{ii) In-depth Interviews with MEN}

Format: Encourage "storytelling" about the relationship and pregnancy/birth Be receptive to expressions of uncertainty and ambivalence

Sample: $\quad$ Partners of women, if possible

\section{Questions}

Probes

1. Let's talk about your current marriage (or current relationship).

○ How long have you been together? How did you meet?

- Are you living together? With parents or other family members?

How have you supported yourselves economically? Are your parents (and other family members) happy about this relationship?

2. Have there been any children from this marriage/relationship? How many children do you have with her?

IF YES: Let's talk about the children you've had with this wife/partner.

- How did you feel about having a child at that time?

- What about your partner - did she want to have a child?

- IF DIFFERENT PREFERENCES: How did you resolve this difference?

- IF DIFFERENT PREFERENCES WERE NOT RESOLVED, OR IF BOTH DID NOT WANT A CHILD: How did it happen that you had a child?

3. Have there been any pregnancies in this relationship that did not lead to a live birth? IF YES:

- When did this occur? (IN RELATION TO LIVE BIRTHS)

- How did you feel about your partner becoming pregnant at that time?

PROCEED CHILD-BY-

CHILD, FIRST CHILD

FORWARD TO MOST

RECENT CHILD. FOR

EACH CHILD, FIRST

ASCERTAIN NAME AND

CURRENT AGE OF CHILD

ASK FOR REASONS WHY. 
○ What about your partner - how did she feel?

- IF DIFFERENT PREFERENCES: How did you resolve this difference?

PROBE EFFORTS TO PREVENT PREGNANCY

- IF DIFFERENT PREFERENCES WERE NOT RESOLVED, OR IF BOTH DID NOT WANT: How did it happen that she became pregnant?

- IF NOT ALREADY CLEAR: What happened with that pregnancy - how did it end? How many weeks/months was the pregnancy when it ended?

4. Now let's talk about the present.

- Would you like to have (more) children? IF YES: How soon?

○ Does your wife/partner want more?

- IF NO MORE OR WANTS TO POSTPONE: What are you and your partner doing to avoid getting pregnant?

- IF NO MORE OR WANTS TO POSTPONE, BUT DOING NOTHING:

You said you don't want your partner to get pregnant now, but you aren't doing anything to avoid pregnancy. Why not?

- IF NO MORE OR WANTS TO POSTPONE: If your partner were to become pregnant, how would you feel? What would be your reaction? Would you consider doing anything to end the pregnancy? IF YES: What might you do?

THIS DISCUSSION IS

CRITICAL: PROBE IN

DEPTH

FACTORS AFFECTING

DESIRE?

CONVICTION vs.

AMBIVALENCE

INTENSITY OF DESIRE

METHODS/TECHNIQUES

BEING USED?

FOR HOW LONG?

SOURCE OF INFORMATION

AND SUPPLIES

PROBE ACTIONS THAT

WOULD BE TAKEN.

PROBE HOW HE WOULD

INVOLVE WOMAN (AND

ANYONE ELSE) IN THE

DECISION 


\section{IF NOT COVERED BY EARLIER DISCUSSION:}

5. Have you and your partner ever tried to plan when she would become pregnant?

Did you ever have an unplanned pregnancy?

Did you do anything about it? How did you decide what to do?
PROBE THE

CIRCUMSTANCES, AND

HOW THE MAN FELT.

PROBE HIS PERCEPTIONS OF PARTNER'S FEELINGS. IF NOT ALREADY CLEAR, PROBE ON HOW HE VIEWS PREGNANCY

PREVENTION/CONTRACE

PTION RELATIVE TO ENDING PREGNANCY/ABORTION. 


\section{Appendix C: Guidelines for Focus Group Discussions}

\section{Women and men}

OBJECTIVES:

- To learn how women/men talk about social norms regarding abortion and contraception

- To learn how women/men perceive contextual influences on abortion and contraceptive behavior

- To learn how women/men view the relative choice of contraception and abortion for preventing pregnancy

INTRODUCTION:

- Participant registration form

- Reasons for conducting this study/who is conducting study/how participants chosen

- Informed consent

\section{Introduction}

1. What is considered as ideal family size in this community? Advantages and disadvantages of having more or less than ideal family size?

2. What is local perception about family planning?

3. Do people in this community generally plan when to have children? Do unplanned pregnancies occur in this community? Why do you say this? Probe on sources of influence.

4. Why do people in this community have unplanned pregnancies? .

\section{Pregnancy avoidance}

1. Some people take measures to avoid pregnancy. What measures do you know that are acceptable in this community? What measures are not acceptable?

2. In this community, how are decisions usually made about using contraception? (PROBE: Who is involved, who has more influence) 
3. What if a woman decided to contracept without her partner's knowledge? What if a man decided to contracept without his partner's knowledge?

4. What do women in this community do if they become unexpectedly pregnant? What do men do if their partners become unexpectedly pregnant? Probe for psychosocial and monetary costs to access contraception and abortion.

5. What would happen to a woman in this community if she had a pregnancy outside of marriage? What would happen to a man if he had a child outside of marriage (relationship)?

\section{Abortion}

1. How do people in this community view abortion? When you hear the word, "abortion", what does it signify?

2. [EXPLANATION TO OFFER] A pregnancy may not end in a live birth. A pregnancy can be lost through miscarriage and a pregnancy can be voluntarily terminated (abortion). We would like to discuss community views on the latter.

3. How would people in this community react to a woman to having an abortion? What would be the community's reaction to a man helping his female partner have an abortion?

4. Should people in this community be able to obtain an abortion if their contraception fails? (PROBE how this may vary by type of contraceptive method)

5. Are there circumstances when a woman should be allowed to have an abortion? For example, if they are unmarried, poor, young, in poor health? Should a man be allowed to help his female partner have an abortion?

6. If a woman in this community secretly obtains an abortion, what is likely to happen to her if her husband/partner finds out? What if family or other community members find out?

7. If her or his decision became known to others or more publicly, would there be social sanctions on them? What types of sanctions might arise?

8. Do you know if there are legal circumstances for a woman to have an abortion in this community? (PROBE: incest, rape, endangers mother's life, other legal grounds) 


\section{Options}

1. How easy or difficult is it for women or couples to find abortion providers in this area if they really want to end a pregnancy? How easy or difficult is it for women or couples to find contraceptive service providers if they wanted to avoid getting pregnant? PROBE: Ask about the costs of contraception and abortion in absolute and relative terms.

2. What are some of the reasons people in this community may prefer to obtain an abortion as compared to using contraception? What are some of the reasons for preferences for using contraception as compared to obtaining an abortion? PROBE: Ask about pros and cons.

3. Do you think abortion experiences for women in this area affect how they behave afterward? How about for men? (PROBE: how they manage their fertility, continue risk of unplanned pregnancy, use contraception)

\section{Closing}

1. Is there anything you like to add or ask about what we've discussed that we haven't covered yet?

2. Thank participants for their time. Reassure them about confidentiality of their comments and utility of their contributions for the study and its purposes. 


\section{Appendix D: Glossary}

Dai Traditional birth attendant

Garam Urdu for hot referring to strength of foods, medicines etc.

LHW Lady Health Worker

FIDI Female in-depth interviews

MIDI Male in-depth interviews

FFGD Female focus group discussions

MFGD Male focus group discussions

TBA Traditional birth attendant

Thanda Urdu for cold referring to substances such as foods, medicines etc.

MVA Manual Vacuum Aspiration

Safai Urdu word for cleansing, colloquial for abortion

Jatt A name of a caste 